\title{
Shikonin Inhibits the Migration and Invasion of Human Glioblastoma Cells by Targeting Phosphorylated $\beta$-Catenin and Phosphorylated PI3K/Akt: A Potential Mechanism for the Anti-Glioma Efficacy of a Traditional Chinese Herbal Medicine
}

\author{
Feng-Ying Zhang ${ }^{1,2}$, Yi Hu ${ }^{3}$, Zhong-You Que ${ }^{3}$, Ping Wang ${ }^{1,2}$, Yun-Hui Liu ${ }^{3}$, \\ Zhen-Hua Wang ${ }^{4}$ and Yi-Xue Xue ${ }^{1,2, *}$
}

1 Department of Neurobiology, College of Basic Medicine, China Medical University, Shenyang 110122, China; E-Mails: zhangfengyingcmu@163.com (F.-Y.Z.); pingwang8000@163.com (P.W.)

2 Institute of Pathology and Pathophysiology, China Medical University, Shenyang 110122, China

3 Department of Neurosurgery, Shengjing Hospital of China Medical University, Shenyang 110004, China; E-Mails: hooyie@hotmail.com (Y.H.); 18840042401@163.com (Z.-Y.Q.); liuyunhuicmu@aliyun.com (Y.-H.L.)

4 Department of Physiology, College of Basic Medicine, China Medical University, Shenyang 110122, China; E-Mail: hooyie@sohu.com

* Author to whom correspondence should be addressed; E-Mail: yxxue@mail.cmu.edu.cn; Tel./Fax: +86-24-2295-8989.

Academic Editor: Gopinadhan Paliyath

Received: 23 July 2015 / Accepted: 16 September 2015 / Published: 9 October 2015

\begin{abstract}
Shikonin is an anthraquinone derivative extracted from the root of lithospermum. Shikonin is traditionally used in the treatment of inflammatory and infectious diseases such as hepatitis. Shikonin also inhibits proliferation and induces apoptosis in various tumors. However, the effect of shikonin on gliomas has not been fully elucidated. In the present study, we aimed to investigate the effects of shikonin on the migration and invasion of human glioblastoma cells as well as the underlying mechanisms. U87 and U251 human glioblastoma cells were treated with shikonin at $2.5,5$, and $7.5 \mu \mathrm{mol} / \mathrm{L}$ and cell viability, migration and invasiveness were assessed with CCK8, scratch wound healing, in vitro Transwell migration, and invasion assays. The expression and activity of matrix metalloproteinase-2 (MMP-2) and matrix metalloproteinase-9 (MMP-9) and the expression of phosphorylated $\beta$-catenin ( $\mathrm{p}-\beta$-catenin) and phosphorylated PI3K/Akt were also checked. Results showed that shikonin significantly inhibited the cell proliferation, migration, invasion, and expression of MMP-2
\end{abstract}


and MMP-9 in U87 and U251 cells. The expression of p- $\beta$-catenin showed contrary trends in two cell lines. It was significantly inhibited in U87 cells and promoted in U251 cells. Results in this work indicated that shikonin displayed an inhibitory effect on the migration and invasion of glioma cells by inhibiting the expression and activity of MMP-2 and -9 . In addition, shikonin also inhibited the expression of p-PI3K and p-Akt to attenuate cell migration and invasion and MMP-2 and MMP-9 expression in both cell lines, which could be reversed by the PI3K/Akt pathway agonist, insulin-like growth factor-1 (IGF-1).

Keywords: shikonin; glioma; migration; invasion; $\beta$-catenin; phosphorylated PI3K/Akt

\section{Introduction}

Gliomas refer to a big family of neuroepithelial tumors consisting of astrocytomas, oligodendrogliomas, anaplastic astrocytomas, and glioblastoma multiforme [1,2]. Glioblastoma multiforme (GBM), accounting for $50 \%-60 \%$ of gliomas and $20 \%$ of all intracranial tumors, is the most common and most malignant among gliomas [3,4]. It has been reported that the median survival of GBM is 6-14 months, two-year survival rate is only 10\%, and five-year survival is less than 5\% [5-7]. The biological properties of GBM are high malignancy, strong proliferation, rapid migration, intensive invasion, and a very poor prognosis [8]. Although there have been great achievements in neuroimaging, neurosurgical techniques, and radiotherapy as well as the molecular understanding in tumorigenesis, the prognosis for patients with gliomas still remains very poor [6,9].

Rapid migration and aggressive invasiveness are major pathobiological characteristics of GBM that contribute to the malignancy and resistance to therapy as well as the recurrence of this disease [10]. For example, perivascular invading has been shown to be vital in the development of GBM [11]. Migration and invasion are also responsible for the existence of multifocal and subclinical lesions, which may limit the conventional therapeutic efficacy. Therefore, it is absolutely vital to develop new agents and therapies to prevent the migration and invasion of glioblastoma, which is still considered incurable [12]. Recently, the therapeutic effects of traditional Chinese medicine on glioblastoma have been paid more attention by researchers. Various agents extracted from Chinese traditional medicine have been verified to have inhibitory effects against glioblastoma cells $[8,13,14]$. Therefore, drugs from Chinese herbs, such as shikonin, might be new hope in the battle against glioblastoma.

Shikonin is an anthraquinone derivative extracted from the root of lithospermum, a traditional Chinese herb. Shikonin has been traditionally employed in the treatment of a variety of inflammatory and infectious diseases such as hepatitis and HIV infection due to its antioxidant, anti-inflammatory, antithrombotic, and wound healing effects [15]. Recently, it has been confirmed that shikonin takes part in various anticancer activities such as suppressing proliferation and inducing apoptosis in human lung adenocarcinoma cells, attenuating invasion and migration in human breast cancer cells, inhibiting prostate cancer cell metastasis, and inducing autophagy in human hepatocellular and pancreatic cancer cells [16-20]. Thus the potential value of shikonin in the therapy of glioblastoma has become an exciting and interesting topic. Unfortunately, studies about the effects of shikonin on gliomas have been quite insufficient. Our previous data revealed that shikonin inhibited cell growth and triggered apoptosis in 
glioma cells and glioma stem cells [21]. Multiple mechanisms are involved in the shikonin-induced apoptosis $[22,23]$. However, the effect of shikonin on other malignant behaviors of glioma cells has not been reported yet.

$\mathrm{Wnt} / \beta$-catenin signaling pathway is involved in a wide set of cellular activities such as morphogenesis, differentiation, and proliferation. $\beta$-Catenin is the key component of $\mathrm{Wnt} / \beta$-catenin signaling pathway and nuclear $\beta$-catenin is the hallmark of an active Wnt pathway [24]. In the absence of the Wnt signals, $\beta$-catenin will be phosphorylated by casein kinase $1-\alpha(\mathrm{CK} 1 \alpha)$ and glycogen synthase kinase-3 $\beta$ (GSK-3 $\beta$ ) in sequence on a intracellular multiprotein destruction complex consisting of adenomatous polyposis coli (APC), axin, and GSK-3 $\beta$; then phosphorylated $\beta$-catenin ( $\mathrm{p}$ - $\beta$-catenin) will be ubiquitinated and degraded by the E3 ligase $\beta$-transducin repeat containing protein $[24,25]$. The alteration of the Wnt signaling components, including the mutation of APC and $\beta$-catenin, is believed to be linked to oncogenesis [26]. Over-expression, abnormal accumulation, or aberrant degradation of $\beta$-catenin are responsible for the occurrence of gliomas [25,27]. As described above, $p$ - $\beta$-catenin is the first step and the target in the degradation of $\beta$-catenin. Here, we hypothesized that shikonin might inhibit glioblastoma cells by attenuating other malignant properties of glioma such as migration and invasion. Alteration of p- $\beta$-catenin might also be involved in this process.

In this study, we aimed to investigate the effects of shikonin on the migration and invasion of human glioblastoma cells as well as the underlying mechanisms, which might benefit the future therapy for malignant gliomas.
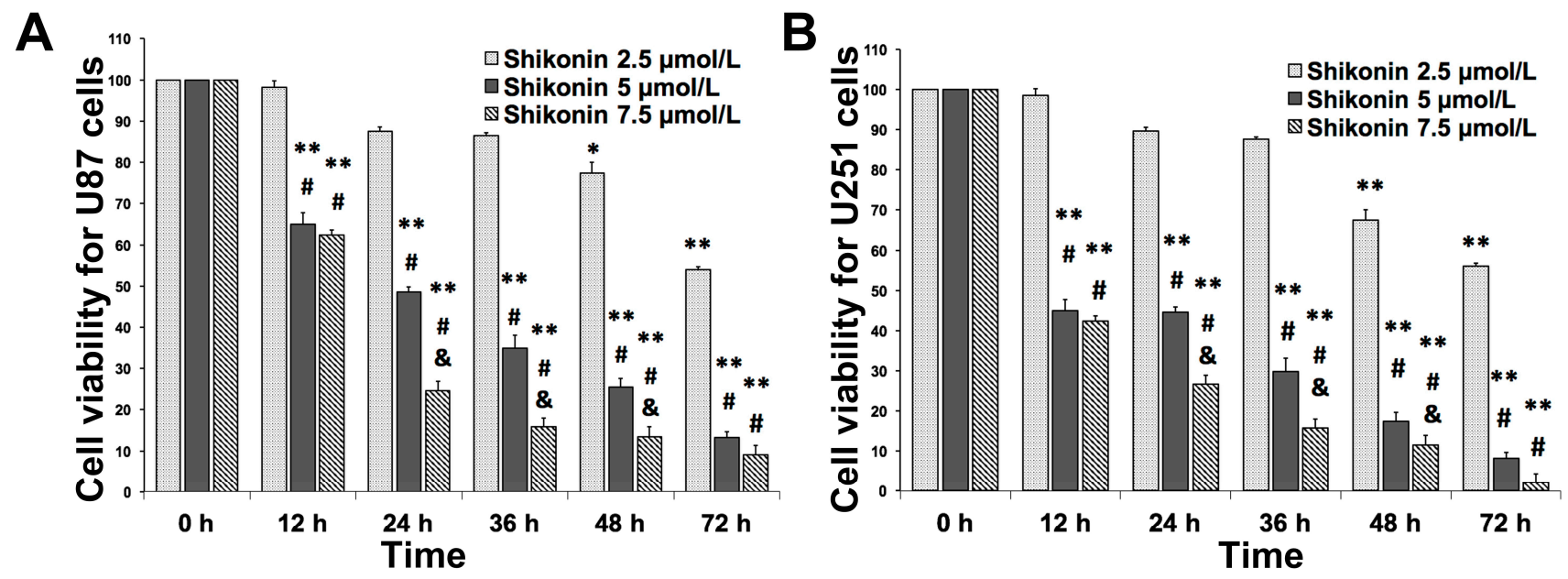

Figure 1. Effects of shikonin on the proliferation of U87 and U251 cells. U87 and U251 cells were treated with shikonin at $2.5,5$, and $7.5 \mu \mathrm{mol} / \mathrm{L}$ for $0-72 \mathrm{~h}$. The cell viability rate was assayed by CCK-8. Shikonin inhibited the proliferation of both cell lines in a time-dependent manner. Doses of 5 and $7.5 \mu \mathrm{mol} / \mathrm{L}$ led to stronger inhibition than $2.5 \mu \mathrm{mol} / \mathrm{L}$. A dose of $7.5 \mu \mathrm{mol} / \mathrm{L}$ displayed the strongest inhibitory effect from 24 to $48 \mathrm{~h}$ and the difference between 5 and $7.5 \mu \mathrm{mol} / \mathrm{L}$ was not significant at 12 and $72 \mathrm{~h}$. (A) CCK-8 results of U87 cells; (B) CCK-8 results of U251 cells. Data is given as mean \pm SD of individual experiments with five plates in each experiment. ${ }^{*} p<0.01$ vs. $0 \mathrm{~h} ;{ }^{* *} p<0.01 v s .12 \mathrm{~h} ;{ }^{*} p<0.01 v s .2 .5 \mu \mathrm{mol} / \mathrm{L}$; ${ }^{\&} p<0.01$ vs. $5 \mu \mathrm{mol} / \mathrm{L} .(n=5)$. 


\section{Results}

\subsection{Shikonin Inhibited the Proliferation of U87 and U251 Cells in Time- and Dose-Dependent Manners}

We first investigated the effects of shikonin on the proliferation of U87 and U251 cells. The cell viability rate was assessed with the CCK8 method. Both cell lines were treated with shikonin at concentrations of 2.5, 5, and 7.5 $\mu \mathrm{mol} / \mathrm{L}$ for $0-72 \mathrm{~h}$. As shown in Figure 1, no obvious inhibitory effect on proliferation could be obtained from $0-36 \mathrm{~h}$ in $2.5 \mu \mathrm{mol} / \mathrm{L}$ group. However, treatments of shikonin at 5 and $7.5 \mu \mathrm{mol} / \mathrm{L}$ significantly inhibited the cell viability starting from $12 \mathrm{~h}$ and the inhibitory effects were presented in time-dependent patterns compared with the $0 \mathrm{~h}$ group in both cell lines. From the results of CCK8, we also found that $5 \mu \mathrm{mol} / \mathrm{L}$ shikonin displayed greater inhibition compared to $2.5 \mu \mathrm{mol} / \mathrm{L}$ at the time points from 24 to $48 \mathrm{~h}$. At 12 and $72 \mathrm{~h}$, no obvious changes were observed between 2.5 and $5 \mu \mathrm{mol} / \mathrm{L}$. Moreover, significant proliferation inhibition was observed in 5 and $7.5 \mu \mathrm{mol} / \mathrm{L}$ groups compared with the $2.5 \mu \mathrm{mol} / \mathrm{L}$ group at each time point. These results indicated that shikonin inhibited the proliferation of U87 and U251 cells in time- and dose-dependent patterns. The cell viability decreased to a very low level in all groups at $72 \mathrm{~h}$ and there was no significant difference between 5 and $7.5 \mu \mathrm{mol} / \mathrm{L}$ at this time point.

\subsection{Shikonin Attenuated the Migration of U87 and U251 Cells}

Since shikonin inhibited the proliferation of U87 and U251 cells in a time- and dose-dependent manner, we next investigated the effects of shikonin on the migration of human glioblastoma cells by the means of in vitro Transwell migration and scratch wound healing assays according to the literature [8]. U87 and U251 cells were treated with shikonin at $2.5,5$, and $7.5 \mu \mathrm{mol} / \mathrm{L}$ for $0-72 \mathrm{~h}$. Results of the wound healing assay are shown in Figure 2A-D. The ratio of cell free area increased significantly by shikonin in U87 cells (Figure 2A,C) and U251 cells (Figure 2B,D) compared to the control group at $24 \mathrm{~h}$ $(p<0.05)$, meaning that cell healing over scratch was inhibited by the treatment of shikonin. At $48 \mathrm{~h}$, the inhibitory effect was even larger $(p<0.01)$. The two higher concentrations showed greater inhibitory effects than $2.5 \mu \mathrm{mol} / \mathrm{L}$, whereas there was no significant difference between 5 and $7.5 \mu \mathrm{mol} / \mathrm{L}$.

A

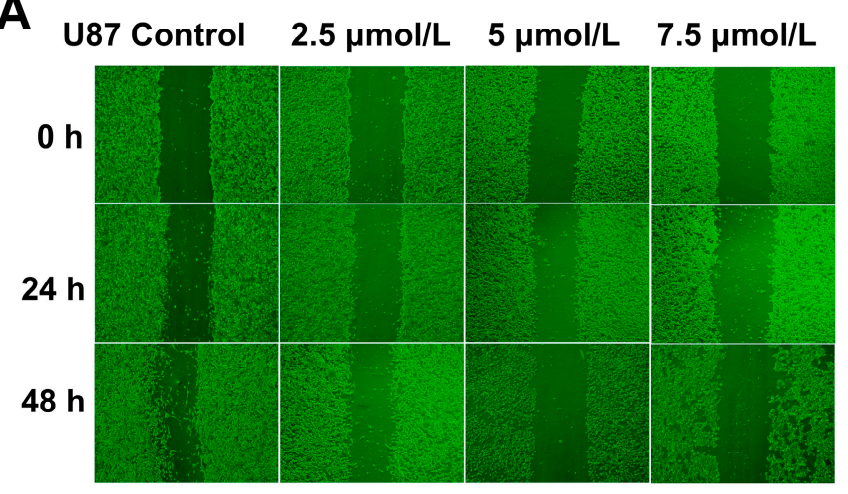

B

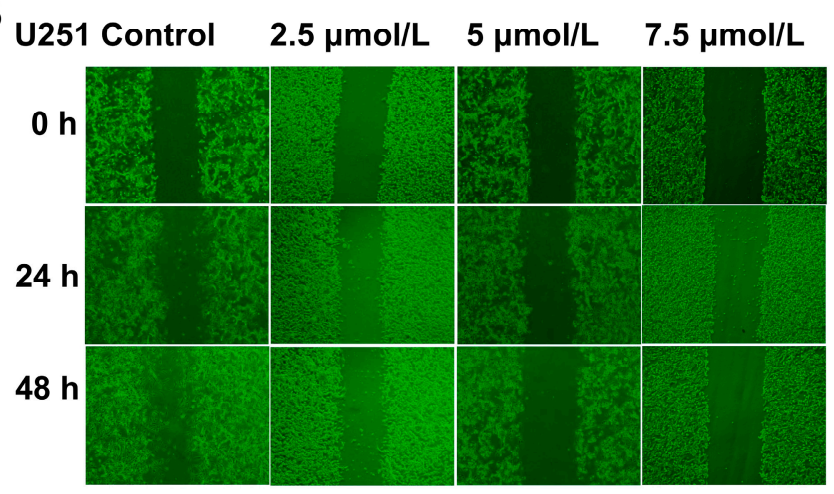

Figure 2. Cont. 


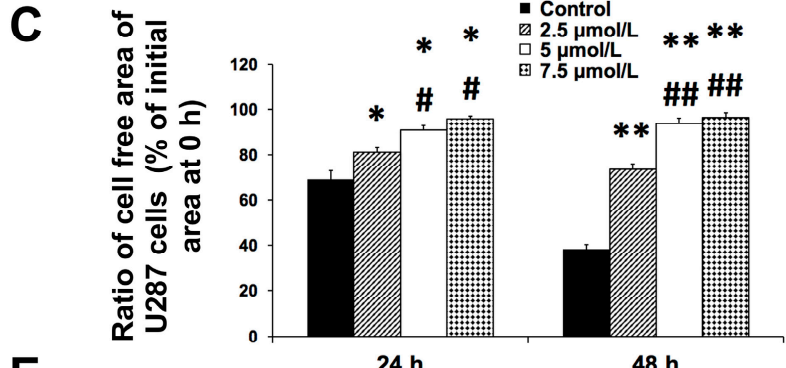

E U87 Control $\quad 2.5 \mu \mathrm{mol} / \mathrm{L} \quad 5 \mu \mathrm{mol} / \mathrm{L}^{48 \mathrm{~h}} 7.5 \mu \mathrm{mol} / \mathrm{L}$

$24 \mathrm{~h}$

$48 \mathrm{~h}$

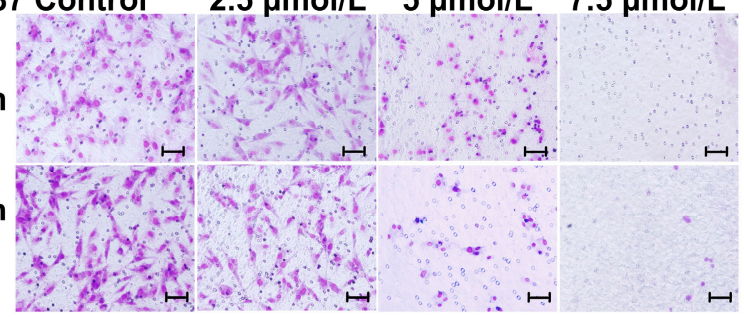

G

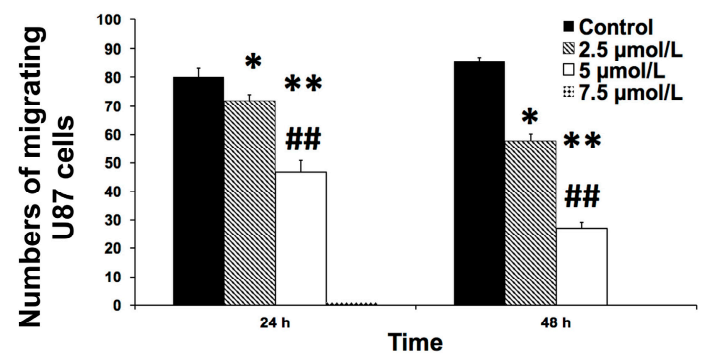

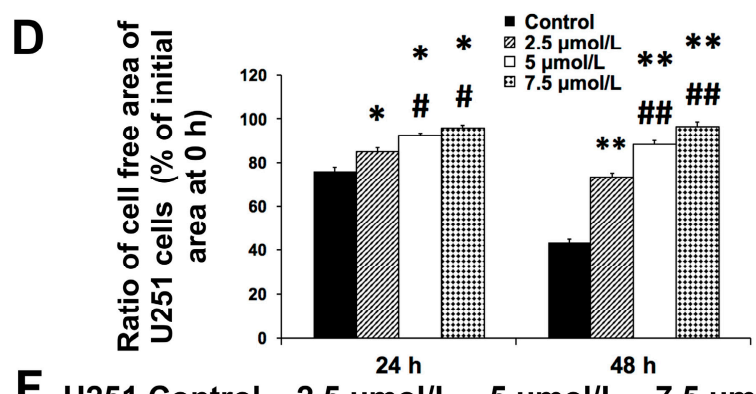

F U251 Control $2.5 \mu \mathrm{mol} / \mathrm{L} \quad 5 \mu \mathrm{mol} / \mathrm{L} \quad 7.5 \mu \mathrm{mol} / \mathrm{L}$

$24 \mathrm{~h}$

$48 \mathrm{~h}$
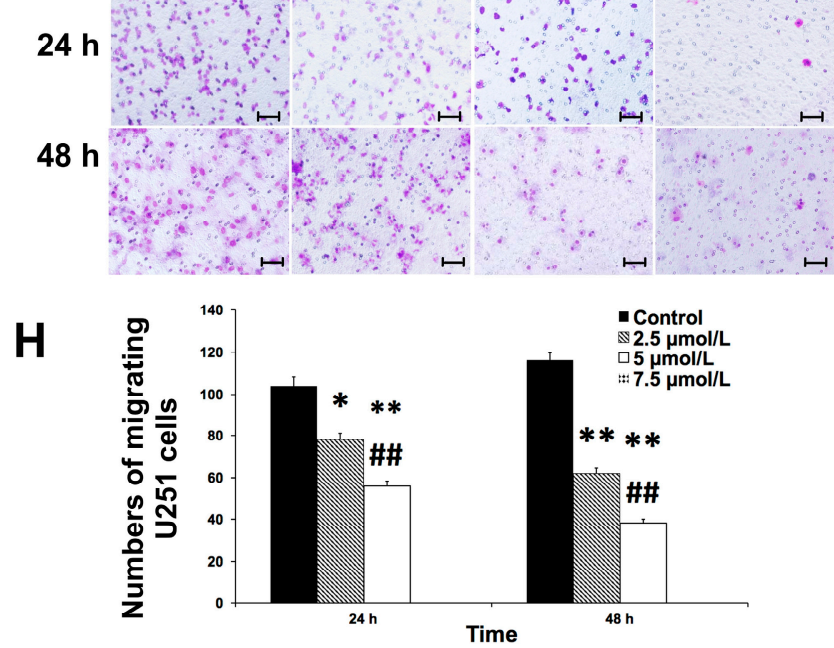

Figure 2. Effects of shikonin on the migratory capacity of glioma cells in vitro. U87 and U251 cells were treated with shikonin at $2.5,5$, and $7.5 \mu \mathrm{mol} / \mathrm{L}$ for $0-48 \mathrm{~h}$. Wound healing and Transwell in vitro migration assays were performed to investigate the changes of migratory capacity of glioblastoma cells under the treatment of shikonin. (A) Results of wound healing assay for U87 cells; (B) Results of wound healing assay for U251 cells; (C) Statistical analysis of wound healing assay for U87 cells. Doses of 2.5 and $5 \mu \mathrm{mol} / \mathrm{L}$ significantly inhibited migration compared with the control group at $24 \mathrm{~h}$. Both concentrations showed significant inhibition on migration at $48 \mathrm{~h}$. However, $5 \mu \mathrm{mol} / \mathrm{L}$ displayed even greater inhibition at $48 \mathrm{~h}$; (D) Statistical analysis of wound healing assay for U251 cells; (E) Results of in vitro Transwell migration assay for U87 cells; (F) Results of Transwell in vitro migration assay for U251 cells. U251 cells were treated similarly to U87 cells; (G) Statistical analysis of migration assay for U87 cells. Doses of 2.5 and $5 \mu \mathrm{mol} / \mathrm{L}$ significantly inhibited the migration ability of U87 cells compared with the control group at $24 \mathrm{~h}$. A dose of $5 \mu \mathrm{mol} / \mathrm{L}$ displayed even greater inhibition at $48 \mathrm{~h}$; (H) Statistical analysis of migration assay for U251 cells. * $p<0.05, * * p<0.01 v s$. control group; ${ }^{\#} p<0.05,{ }^{\#} p<0.01$ vs. $2.5 \mu \mathrm{mol} / \mathrm{L}(n=5)$. Bar stands for $50 \mu \mathrm{m}$. Original magnification of $\mathbf{A}, \mathbf{B}: \times 200 ; \mathbf{E}, \mathbf{F}: \times 400$.

The above results of the wound healing assay were supported by the in vitro Transwell migration assay. As shown in Figure 2E-H, the numbers of cells migrating to the downside surface of filter in the 2.5 and $5 \mu \mathrm{mol} / \mathrm{L}$ groups decreased significantly compared with the control group at 24 and $48 \mathrm{~h}$ in both cell lines and $5 \mu \mathrm{mol} / \mathrm{L}$ showed greater inhibitory effect. However, few cells migrated to the lower side of the filter at a concentration of $7.5 \mu \mathrm{mol} / \mathrm{L}$. All the results described above indicated that shikonin inhibited the migrating ability of human glioblastoma cells in a dose-dependent manner, although the 
effect of $7.5 \mu \mathrm{mol} / \mathrm{L}$ probably reached the plateau and seemed too strong in wound healing and in vitro migration assays.
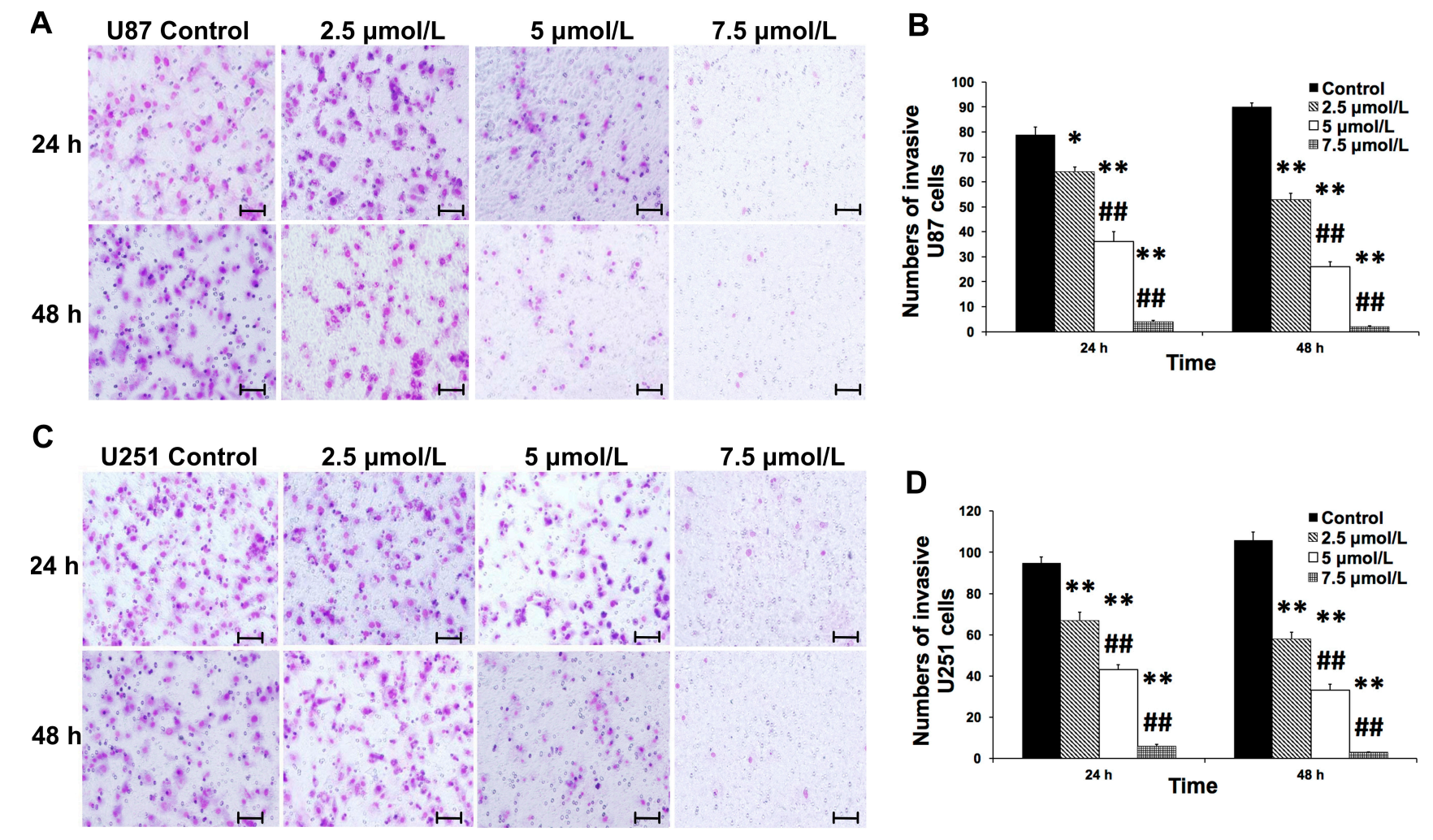

Figure 3. Effects of shikonin on the invasive capacity of glioma cells (A) Results of Transwell in vitro invasion assay for U87 cells. In vitro invasion assay was performed to investigate the changes of invasive capacity of U87 cells under the treatment of shikonin. U87 cells were treated with shikonin at 2.5, 5, and $7.5 \mu \mathrm{mol} / \mathrm{L}$ for $0-48 \mathrm{~h}$; (B) Statistical analysis for U87 cells. Doses of 2.5 and $5 \mu \mathrm{mol} / \mathrm{L}$ significantly inhibited the invasive ability of U251 cells compared with control groups at $24 \mathrm{~h}$. A dose of $5 \mu \mathrm{mol} / \mathrm{L}$ displayed even greater inhibition at $48 \mathrm{~h}$; (C) Results of Transwell in vitro invasion assay for U251 cells. In vitro invasion assay was performed to investigate the changes of invasive capacity of U251 cells under the treatment of shikonin. U251 cells were treated with shikonin at 2.5, 5, and $7.5 \mu \mathrm{mol} / \mathrm{L}$ for $0-48 \mathrm{~h}$; (D) Statistical analysis for U251 cells. ${ }^{*} p<0.05,{ }^{* *} p<0.01$ vs. control group; ${ }^{\#} p<0.01$ vs. $2.5 \mu \mathrm{mol} / \mathrm{L}(n=5)$. Bar stands for $50 \mu \mathrm{m}$. Original magnification of $\mathbf{A}, \mathbf{C}: \times 400$.

\subsection{Shikonin Inhibited the Invasion of Human Glioblastoma Cells}

Highly invasive growth is one of the most important properties of glioblastoma that contributes to the malignancy of this disease [10]. In the present study, we also aimed to investigate the effects of shikonin on the invasiveness of human glioblastoma cells by Transwell invasion assay. The results are shown in Figure 3. The invasiveness of U87 (Figure 3A,B) and U251 cells (Figure 3C,D) was significantly attenuated when treated with shikonin at $2.5,5$, and $7.5 \mu \mathrm{mol} / \mathrm{L}$ compared with the control group at 24 and $48 \mathrm{~h}(p<0.01)$. The inhibitory effect on the invasion of U87 and U251 cells increased significantly 
with ascending concentrations of shikonin. This result indicated that the invasion of human glioblastoma cells was reduced by the treatment of shikonin in a dose-dependent manner.

A

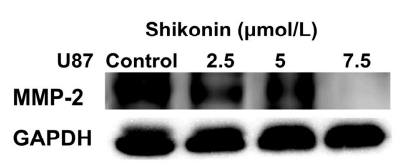

C

E

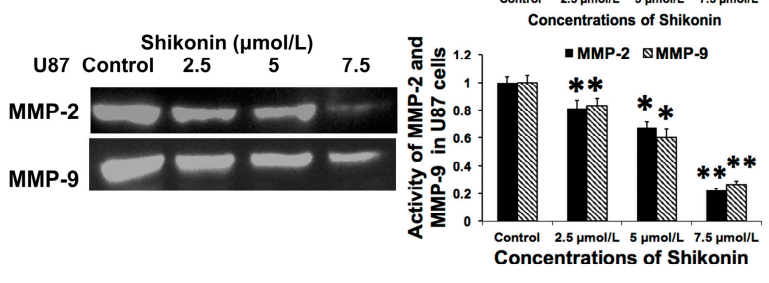

B

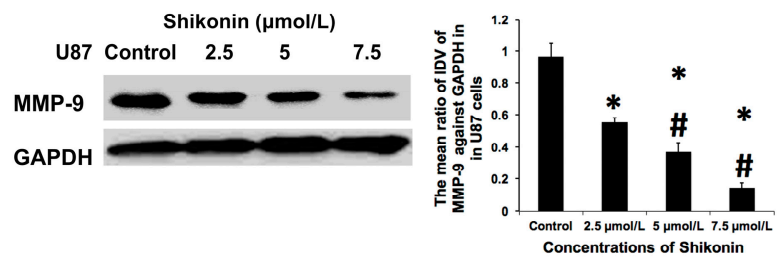

D

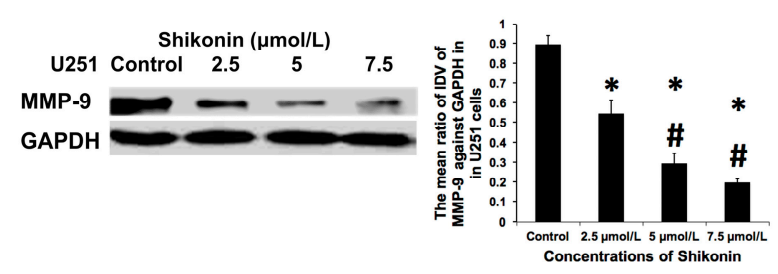

$\mathbf{F}$

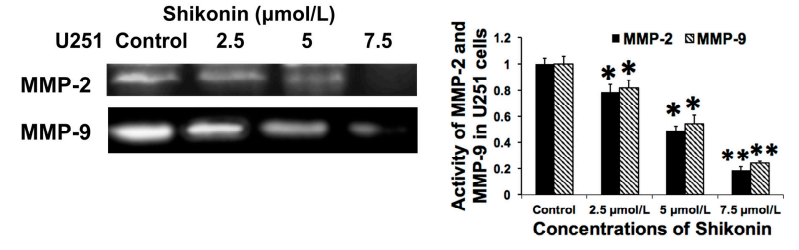

Figure 4. Shikonin inhibited the expression and activity of MMP-2 and MMP-9. U87 and U251 cells were treated with shikonin at $2.5,5$, and $7.5 \mu \mathrm{mol} / \mathrm{L}$ for $48 \mathrm{~h}$. Serum free DMEM served as a negative control. Expressions of MMP-2 and MMP-9 were checked with Western Blot. (A) Effects of shikonin on the expression of MMP-2 in U87 cells; (B) Effects of shikonin on the expression of MMP-9 in U87 cells; (C) The changing pattern of MMP-2 in U251 cells; (D) The changing pattern of MMP-9 in U251 cells; (E) Effects of shikonin on the activities of MMP-2 and MMP-9 in U87 cells; (F) Effects of shikonin on the activities of MMP-2 and MMP-9 in U251 cells. Statistical analysis showed that shikonin significantly reduced the expression levels and activity of both MMP-2 and MMP-9 proteins compared with the control group in a dose-dependent manner. $* p<0.05, * * p<0.01$ (compared with control group); ${ }^{\#} p<0.05$ (compared with $2.5 \mu \mathrm{mol} / \mathrm{L}$ groups) $(n=5)$.

\subsection{Shikonin Inhibited the Expression and Activity of Matrix Metalloproteinase-2 and -9}

Matrix metalloproteinase (MMP) 2 and 9 are considered to be important invasion-related proteolylic enzymes that contribute most to the invasion and malignancy of glioblastoma cells [28]. In our previous study, we revealed that artemether, another traditional Chinese herbal extract, inhibited MMP-2 and 9 in a dose-dependent manner [8]. In the present study, we also tried to investigate whether shikonin could regulate the expression and activity of MMP-2 and MMP-9. Doses of 2.5, 5 and $7.5 \mu \mathrm{mol} / \mathrm{L}$ shikonin significantly downregulated the protein expression of MMP-2 (Figure 4A) and MMP-9 (Figure 4B) compared with the control group in U87 cell lines and higher concentrations showed greater inhibitory effects. Similar results were observed in U251 cells; the expression of MMP-2 (Figure 4C) and MMP-9 (Figure 4D) was also inhibited by shikonin in a dose-dependent manner. Meanwhile, the activities of MMP-2 and MMP-9 were estimated by gelatin zymography assay. As shown in Figure 4E,F, the enzymatic activity of MMP-2 and MMP-9 showed a similar changing trend to the protein expression. 
The above results indicated that the expression and activity of MMP-2 and -9 were inhibited by shikonin in a dose-dependent manner in both U87 and U251 glioblastoma cell lines.
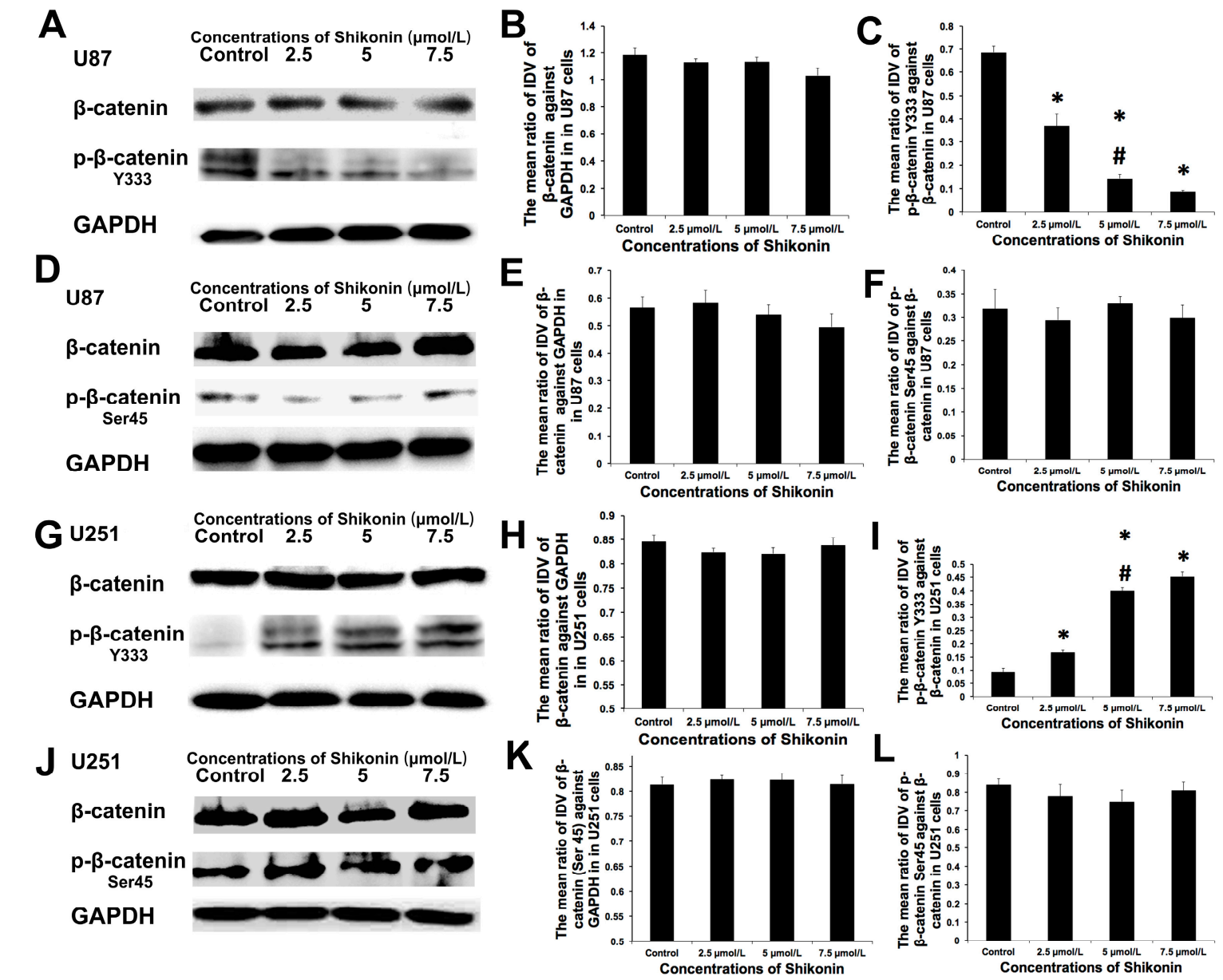

Figure 5. The regulation of $p-\beta$-catenin expression by shikonin. The expression of $p-\beta$-catenin was significantly inhibited by the treatment of shikonin in a dose-dependent manner at Y333 whereas it was not altered at Ser45 in U87 cells. However, there was no significant difference between the concentrations of 5 and $7.5 \mu \mathrm{mol} / \mathrm{L}$ at Y333. U251 cells were treated similarly to U87 cells. The expression of $\mathrm{p}$ - $\beta$-catenin $\mathrm{Y} 333$ was significantly upregulated due to treatment with shikonin. Again, there was no significant difference between the concentrations of 5 and $7.5 \mu \mathrm{mol} / \mathrm{L}$. (A) Western blot assay results of $\beta$-catenin and p- $\beta$-catenin Y333 in U87 cells; (B) Statistical analysis of $\beta$-catenin expression levels in U87 cells; (C) Statistical analysis of p- $\beta$-catenin Y333 expression levels in U87 cells; (D) Western blot assay results of $\beta$-catenin and p- $\beta$-catenin Ser45 in U87 cells; (E) Statistical analysis of $\beta$-catenin expression levels in U87 cells; (F) Statistical analysis of p- $\beta$-catenin Ser45 expression levels in U87 cells; (G) Western blot assay results of $\beta$-catenin and p- $\beta$-catenin Y333 in U251 cells; (H) Statistical analysis of $\beta$-catenin expression levels in U251 cells; (I) Statistical analysis of p- $\beta$-catenin Y333 expression levels in $\mathrm{U} 251$ cells; ( $\mathbf{J})$ Western blot assay results of $\beta$-catenin and $p$ - $\beta$-catenin Ser45 in U251 cells; (K) Statistical analysis of $\beta$-catenin expression levels in U251 cells; (L) Statistical analysis of $p$ - $\beta$-catenin Ser45 expression levels in U251 cells. ${ }^{*} p<0.01$ compared with control group; ${ }^{*} p<0.01$ compared with the former $(n=5)$. 


\subsection{Shikonin Showed Contrary Effects on the p- $\beta$-Catenin Y333 Expression in U87 or U251 Cells}

In this work, Western blot assay was applied to investigate the variation in the expression of $p$ - $\beta$-catenin in U87 and U251 cells under the treatment of shikonin. The expression levels of $\beta$-catenin were not changed obviously by shikonin in U87 cells (Figure 5A,B). However, the mean ratio of the IDV of p- $\beta$-catenin $Y 333$ against $\beta$-catenin decreased significantly in the $2.5,5$, and $7.5 \mu \mathrm{mol} / \mathrm{L}$ groups compared with the control group (Figure $5 \mathrm{~A}, \mathrm{C}$ ), meaning that $\mathrm{p}$ - $\beta$-catenin expression was significantly inhibited by the treatment of shikonin at Y333 site in this cell line. A dose of $5 \mu \mathrm{mol} / \mathrm{L}$ displayed greater inhibitory effect on the p- $\beta$-catenin Y333 expression than $2.5 \mu \mathrm{mol} / \mathrm{L}$. However, there was no significant difference between the concentrations of 5 and $7.5 \mu \mathrm{mol} / \mathrm{L}$. In U251 cells, the expression levels of $\beta$-catenin did not change significantly either (Figure $5 \mathrm{G}, \mathrm{H}$ ). Nevertheless, the change pattern of $\mathrm{p}$ - $\beta$-catenin Y333 expression in U251 cells was contrary to that of U87 cells. P- $\beta$-catenin Y333 expression displayed an increasing trend with elevated concentrations of shikonin (Figure 5G,I). Similarly to U87 cells, no significant difference was observed between the concentrations of 5 and $7.5 \mu \mathrm{mol} / \mathrm{L}$. Western blot analysis revealed that shikonin had contrary effects on the expression of $p$ - $\beta$-catenin in U87 and U251 cells at Y333.

The mean ratio of the IDV of p- $\beta$-catenin showed no obvious change at the site of Ser45 in both cell lines (Figure 5D,E,J-L), indicating that the Ser45 site was not involved in the regulation of p- $\beta$-catenin expression.
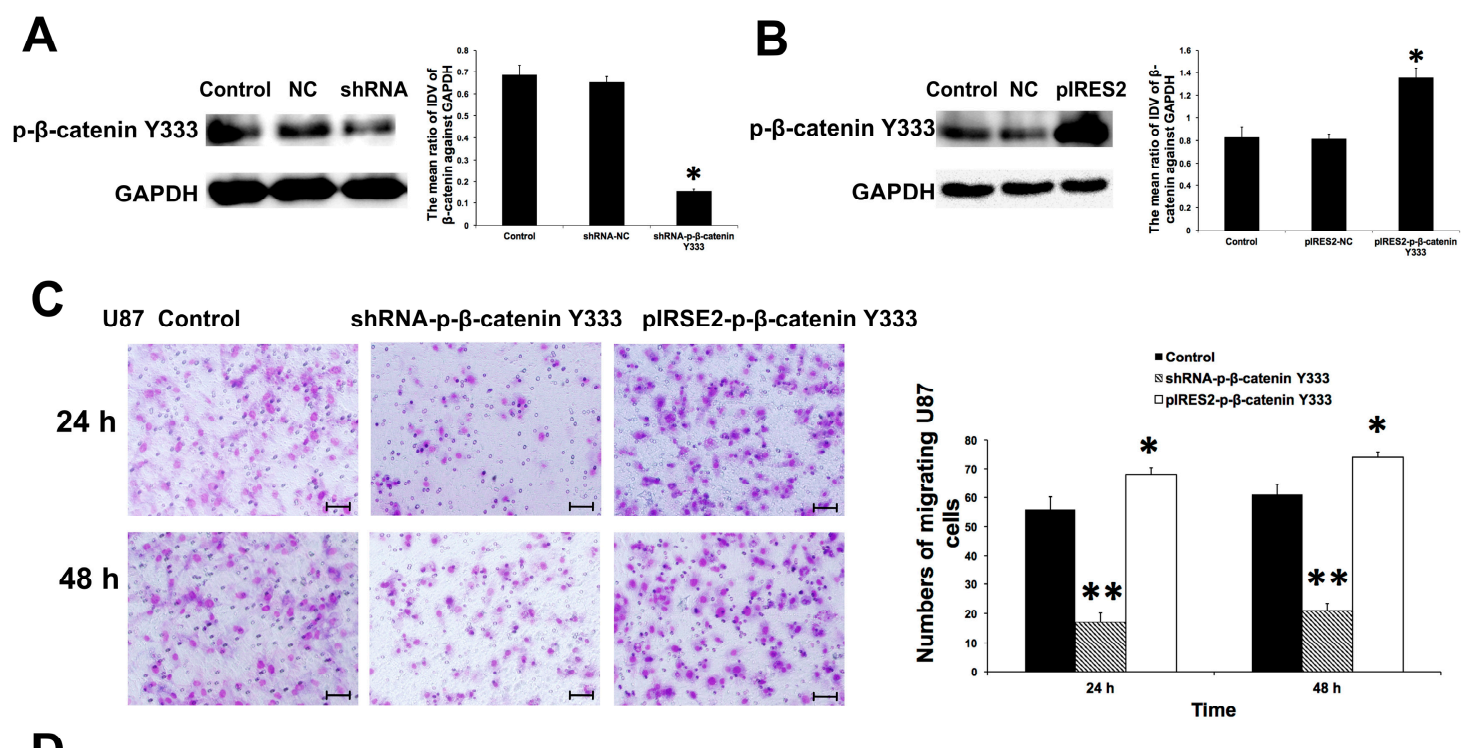

D
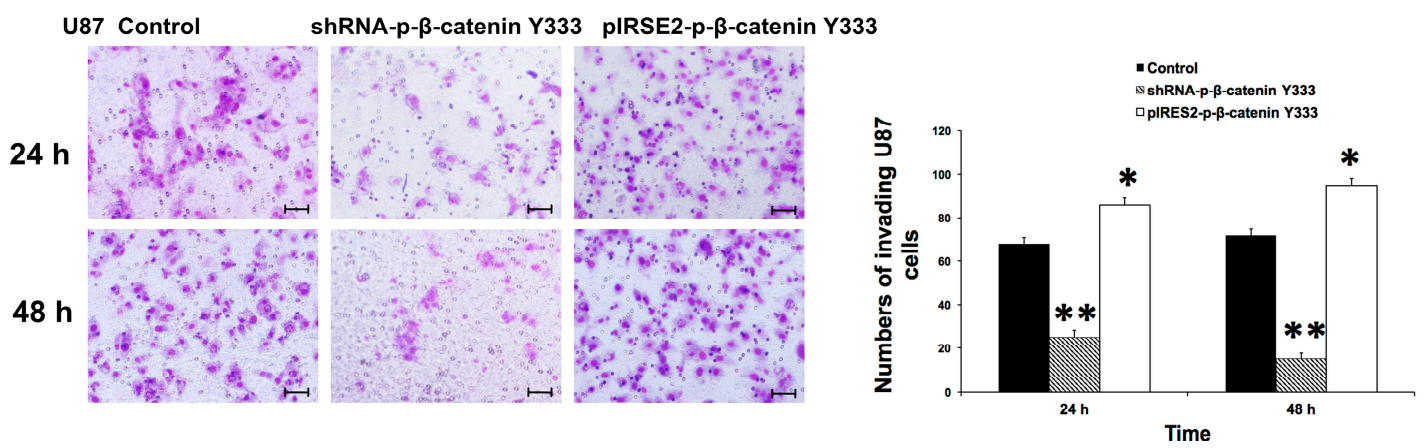

Figure 6. Cont. 
E

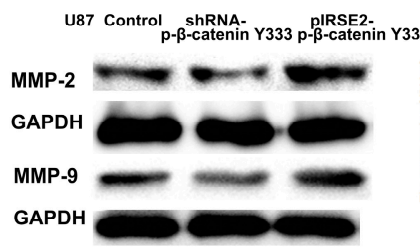

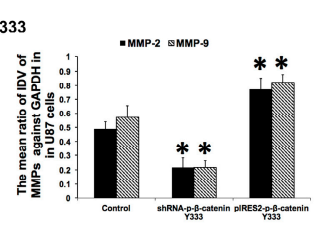

$\mathbf{F}$

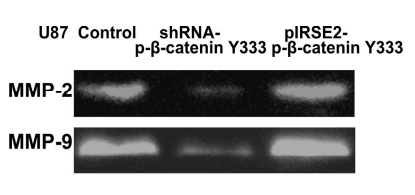

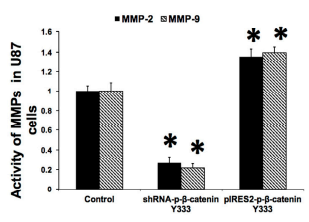

Figure 6. The effects of $p-\beta$-catenin Y333 knockdown or overexpression on the migration, invasion, and MMP expression and activity of U87 cells. The effects of $p$ - $\beta$-catenin on the malignant biological behavior of glioma cells were investigated by establishing stably transfected U87 cells with p- $\beta$-catenin Y333 silencing or overexpression plasmids. $p$ - $\beta$-catenin Y333 knockdown attenuated the migration, invasion, and MMP expression and activity in U87 cells, whereas its overexpression enhanced the malignant biological behavior of glioma cells. (A) The knockdown transfection efficiency. The expression of $p$ - $\beta$-catenin Y333 protein was checked by Western blot assays. p- $\beta$-catenin Y333 was significantly inhibited in the shRNA-p- $\beta$-catenin Y333 group individually compared with the control group. The NC control group showed no obvious difference to the control group; (B) The overexpression transfection efficiency. P- $\beta$-catenin Y333 was significantly upregulated in the pIRES2-p- $\beta$-catenin Y333 group individually compared with the control group. The NC control group showed no obvious difference with the control group; $(\mathbf{C})$ Results of Transwell in vitro migration assay. The migration of U87 cells was either inhibited or promoted by p- $\beta$-catenin Y333 knockdown or overexpression; (D) Results of Transwell in vitro invasion assay. The invasion of U87 cells was either inhibited or promoted by $p$ - $\beta$-catenin Y333 knockdown or overexpression; (E) The effects of p- $\beta$-cateninY333 knockdown or overexpression on the MMP expression of U87 cells assessed by Western blot assay. The expression of MMP-2 and MMP-9 was either inhibited or promoted by $p-\beta$-cateni nY333 knockdown or overexpression; (F) The effects of p- $\beta$-cateninY333 knockdown or overexpression on the MMP-2 and MMP-9 activity of U87 cells. The activity of MMP-2 and MMP-9 was inhibited by $p$ - $\beta$-catenin Y333 knockdown but promoted by p- $\beta$-catenin Y333 over-expression. ${ }^{*} p<0.05, * * p<0.01$ compared with control $(n=5)$. Bar stands for $50 \mu \mathrm{m}$. Original magnification of $\mathbf{A}, \mathbf{C}: \times 400$.

\subsection{P- $\beta$-Catenin Y333 Knockdown or Overexpression Displayed Contrary Effects on the Migration,} Invasion, MMP Expression, and Activity in U87 Cells

The aforementioned results demonstrate that shikonin inhibited the expression of $p$ - $\beta$-catenin Y333 in U87 cells. The role of p- $\beta$-catenin Y333 in the malignant biological behavior of glioma cells was confirmed by establishing stably transfected U87 cells with silencing or over-expression plasmids of p- $\beta$-catenin Y333. The transfection efficiency of $p-\beta$-catenin Y333 was assessed by Western Blot and the results were displayed in Figure 6A,B. The expression of $\mathrm{p}$ - $\beta$-catenin Y333 was inhibited or promoted significantly in the shRNA-p- $\beta$-catenin Y333 (Figure 6A) or pIRES2-p- $\beta$-catenin Y333 (Figure 6B) group compared with the blank group. The NC control group showed no obvious difference to the blank group. The silence and overexpression efficiency were $63 \%$ and $135 \%$, respectively. As 
shown in Figure 6C, cell migration was significantly inhibited in the shRNA-p- $\beta$-catenin Y333 group while it was promoted in the pIRES2-p- $\beta$-catenin Y333 group compared with the control group. The effects of shRNA-p- $\beta$-catenin Y333 and pIRES2-p- $\beta$-catenin Y333 on cell invasion were similar to the results of migration (Figure 6D). As shown in Figure 6E, shRNA-p- $\beta$-catenin Y333 significantly inhibited the expressions of MMP-2 and MMP-9 in U87 cells, whereas pIRES2-p- $\beta$-catenin Y333 promoted them. The effects of shRNA-p- $\beta$-catenin Y333 and pIRES2-p- $\beta$-catenin Y333 on the activity of MMP-2 and MMP-9 were similar to the results of MMP expression (Figure 6F). These results confirmed that $\mathrm{p}$ - $\beta$-catenin Y333 knockdown or overexpression showed contrary effects on the migration, invasion, and MMP expression and activity in U87 cells, indicating that $p$ - $\beta$-catenin Y333 might play a role in the shikonin-induced inhibition of glioma cells.

\subsection{Shikonin Inhibited the Expression of p-PI3K and p-Akt in Both Cell Lines}

As described in the above results, shikonin inhibited the expression of $p$ - $\beta$-catenin Y333 in U87 cells rather than U251 cell, suggesting that $p$ - $\beta$-catenin Y333 might not be the functional element in shikonin-induced inhibition in U251 cells. Phosphoinositide-3-kinase (PI3K)/Akt pathway is important in many cellular activities. We have previously revealed that the PI3K/Akt pathway also played a major role in the malignant behavior of glioma cells such as proliferation and invasiveness [8,29]. Function of shikonin is also associated with the PI3K/Akt pathway [30]. Shikonin promotes autophagy in human pancreatic cancer cells through this signaling pathway [20]. In the present study, we also tried to investigate the role of PI3K/Akt in shikonin-induced inhibition in U87 and U251 cells. As shown in Figure 7A, the expression of Akt or PI3K was not altered by shikonin in U87 (Figure 7A,B). However, the expression levels of $\mathrm{p}$-Akt and p-PI3K were decreased significantly by the administration of 2.5, 5, and $7.5 \mu \mathrm{mol} / \mathrm{L}$ shikonin in U87 cell lines and the inhibitory effect was in a dose-dependent manner (Figure 7A,C). The results in U521 cells were similar to those in U87 cells (Figure 7D-F). These results showed that the PI3K/Akt pathway might also be an important signaling pathway in the shikonin-induced inhibition in both glioma cell lines.

\subsection{PI3K/Akt Pathway Was Involved in the Shikonin-Induced Inhibition of U87 and U251 Cells}

The role of PI3K/Akt pathway in the shikonin-induced inhibition on the malignant behavior of glioma cells was investigated. As shown in Figure 8, shikonin and PI3K/Akt pathway inhibitor LY294002 attenuated the migration, invasion, and MMP expression and activity in U87 and U251 cells and PI3K/Akt pathway agonist IGF-1 could reverse the inhibitory effects of shikonin. As shown in Figure 9, shikonin as well as LY294002 attenuated the expression of p-PI3K and p-Akt in both cell lines, which could be compensated for with IGF-1treatment. These results indicated that the PI3K/Akt pathway was involved in the shikonin-induced inhibition of glioma cell migration and invasion. 

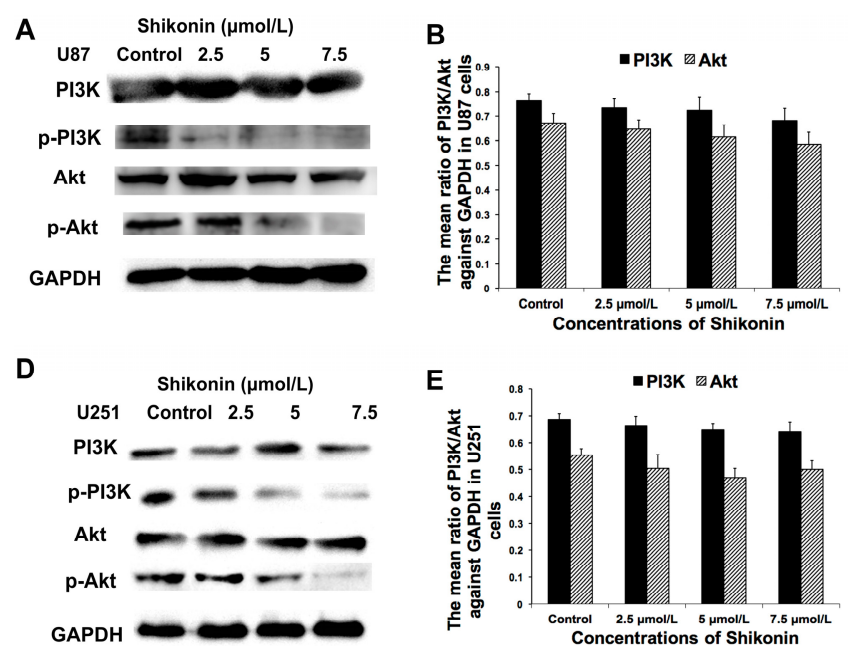

C

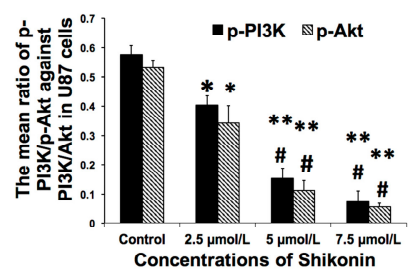

$\mathbf{F}$

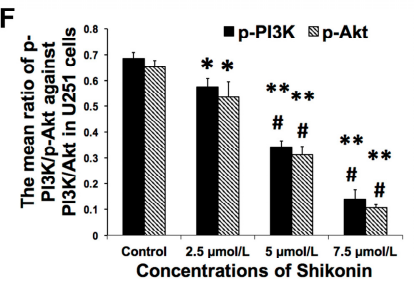

Figure 7. The effects of shikonin on the expression of p-Akt and p-PI3K in glioma cells. U87 and U251 cells were treated with shikonin at 2.5, 5, and $7.5 \mu \mathrm{mol} / \mathrm{L}$ for $48 \mathrm{~h}$. The expression of p-PI3K and p-Akt was inhibited by the treatment of shikonin in a dose-dependent manner in both glioma cell lines. (A) Results of Western blot assay in U87 cells; (B) Statistical analysis of PI3K/Akt expression levels in U87 cells; (C) Statistical analysis of p-PI3K/p-Akt expression levels in U87 cells; (D) Results of Western blot assay in U251 cells; (E) Statistical analysis of PI3K/Akt expression levels in U251 cells; (F) Statistical analysis of $\mathrm{p}-\mathrm{PI} 3 \mathrm{~K} / \mathrm{p}$-Akt expression levels in U251 cells. $* p<0.05, * * p<0.01$ compared with control; ${ }^{\#} p<0.05$ compared with the former concentration. $(n=5)$.

A

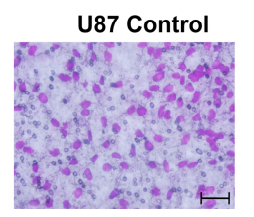
LY294002

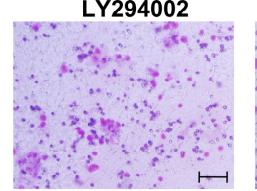

C

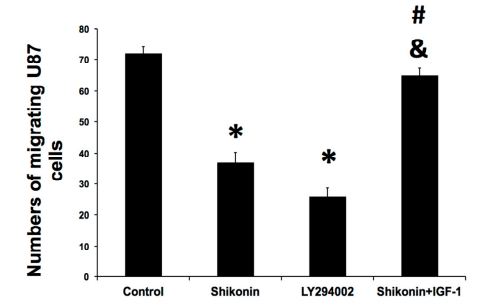

E

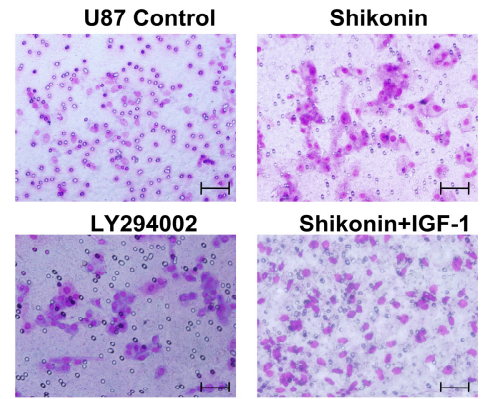

B
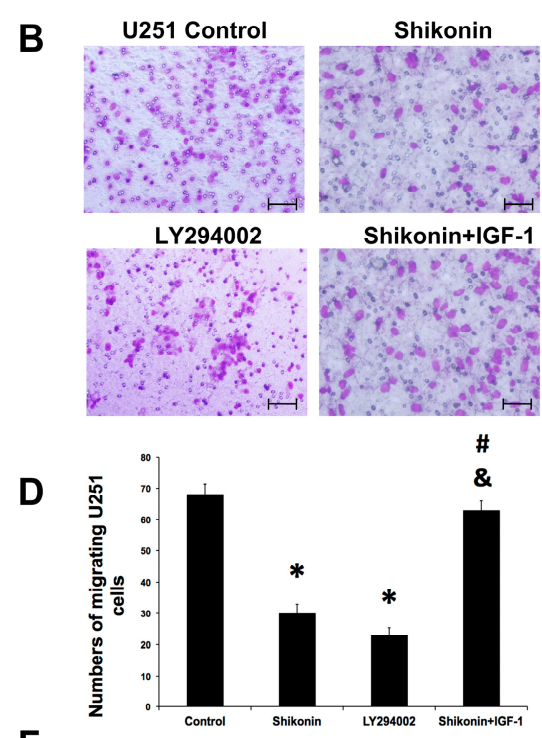

$\mathbf{F}$

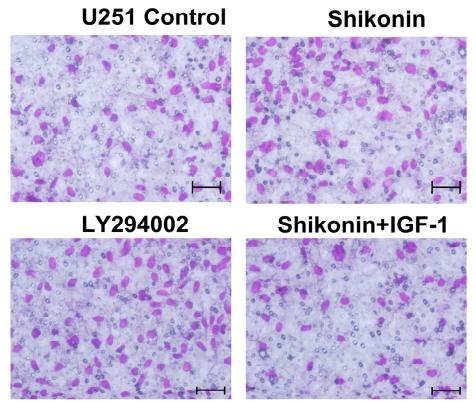

Figure 8. Cont. 


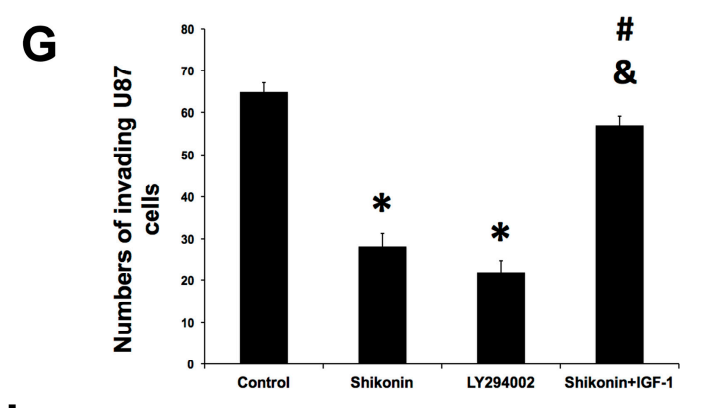

I

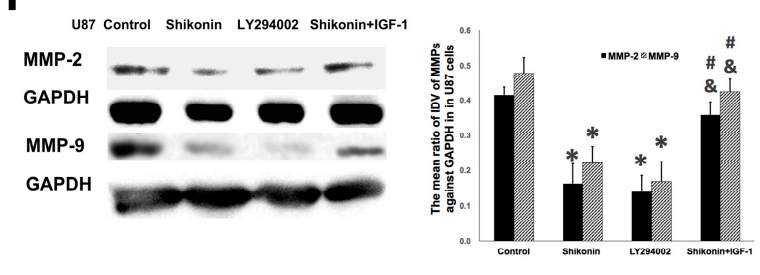

K

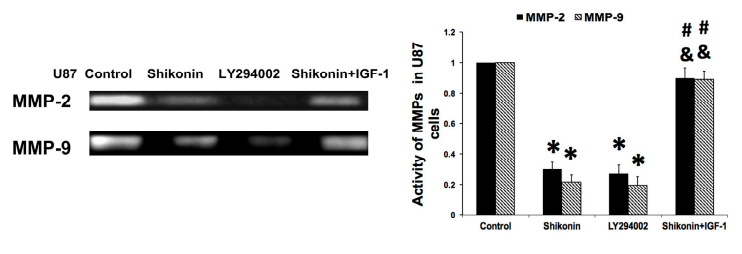

H
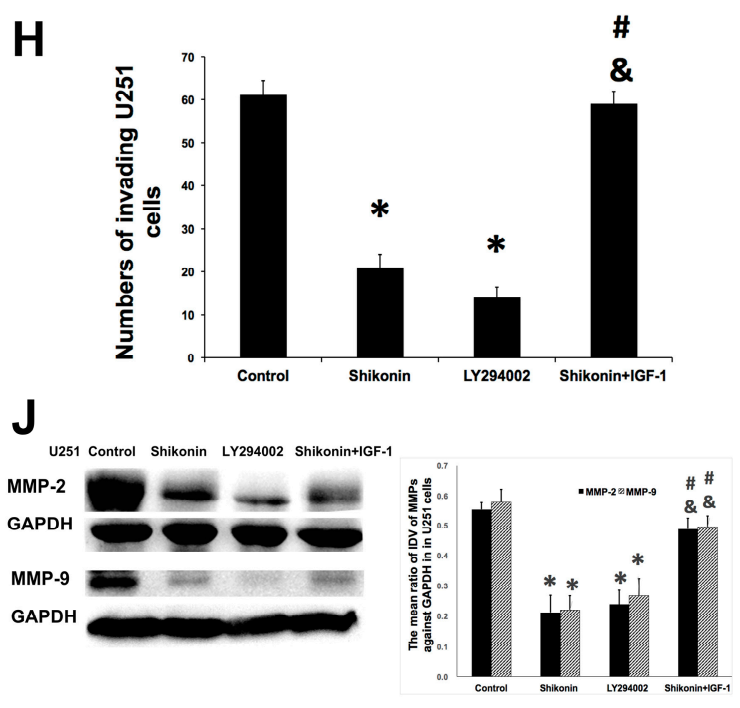

$\mathbf{L}$

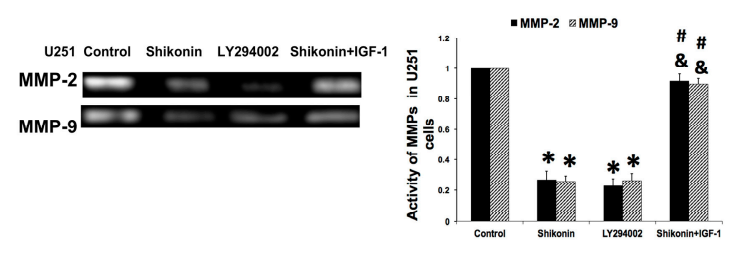

Figure 8. The effects of PI3K/Akt inhibitor or agonist on the migration, invasion, and MMP expression and activity of glioma cells. U87 and U251 cell were treated with shikonin (5 $\mu \mathrm{mol} / \mathrm{L})$, PI3K/Akt inhibitor LY294002 $(20 \mu \mathrm{mol} / \mathrm{L})$, or shikonin combined with the PI3K/Akt agonist IGF-1 $(20 \mu \mathrm{g} / \mathrm{mL})$. Shikonin and LY294002 attenuated the migration, invasion, and MMP expression and activity in both cell lines compared with the control group. Treatment of IGF-1 compensated for the inhibitory effects of shikonin compared with either the shikonin or LY294002 group, indicating that activation of PI3K/Akt could reverse shikonin-induced inhibition. These results showed that PI3K/Akt might also be a target in the process. (A) Results of Transwell in vitro migration assay in U87 cells; (B) Results of Transwell in vitro migration assay in $\mathrm{U} 251$ cells; (C) Statistical analysis of in vitro migration assay for U87 cells; (D) Statistical analysis of in vitro migration assay for U251 cells; (E) Results of in vitro invasion assay in U87 cells; (F) Results of in vitro invasion assay in U251 cells. IGF-1 reversed the shikonin-induced inhibition; (G) Statistical analysis of in vitro invasion assay for U87 cells; (H) Statistical analysis of in vitro invasion assay for U251 cells; (I) Western blot results of MMP-2 and MMP-9 in U87 cells; (J) Western blot results of MMP-2 and MMP-9 in U251 cells; (K) Results of zymography in U87 cells. Shikonin and LY294002 significantly inhibited the activity of MMP-2 and MMP-9 in U87 cells, which could be reversed by IGF-1; (L) Results of zymography in U251 cells. * $p<0.01$, compared with the control; ${ }^{\#} p<0.05$ compared with the shikonin group; ${ }^{\&} p<0.05$ compared with the LY294002 group $(n=3)$. Bar stands for $50 \mu \mathrm{m}$. Original magnification of $\mathbf{A}, \mathbf{B}$ and $\mathbf{E}, \mathbf{F}: \times 400$. 


\section{Discussion}

In the present study, we first verified that shikonin inhibited the proliferation of human malignant glioma U87 and U251 cell lines in a time- and dose-dependent manner. Next, in vitro Transwell migration and scratch wound healing assays were performed to check the effects of shikonin on cell migration and invasion. Results revealed that shikonin inhibited the migration and invasion of U87 and U251 cell lines in a dose-dependent manner. Results of Western blot assay revealed that the expression of p- $\beta$-catenin Y333 was significantly inhibited or upregulated by the treatment of shikonin in U87 or U251 cells. However, $p$ - $\beta$-catenin Ser45 expression was not altered by the treatment of shikonin. Then stable transfection was established to knockdown or overexpress $p$ - $\beta$-catenin Y333. The transfection was verified by Western blot assay. Knockdown of p- $\beta$-catenin Y333 inhibited the cell migration, invasion, and expression and activity of MMP-2 and MMP-9 in U87 cells. Finally, we confirmed that the treatment of shikonin also inhibited the expression of $\mathrm{p}-\mathrm{PI} 3 \mathrm{~K}$ and p-Akt, resulting in attenuated cell migration, invasion, and MMP-2 and MMP-9 expression and activity in both cell lines, which could be reversed by PI3K/Akt pathway agonist IGF-1.

A

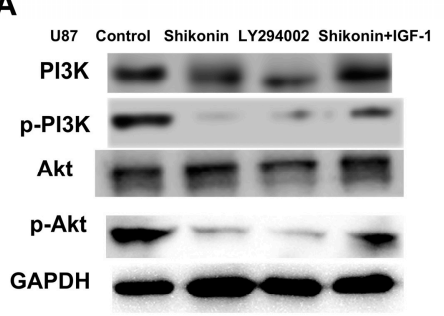

D

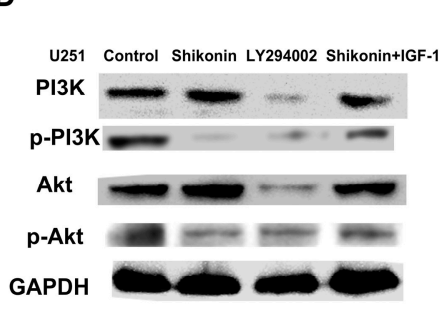

B

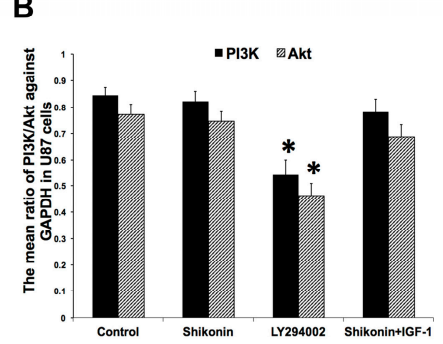

E

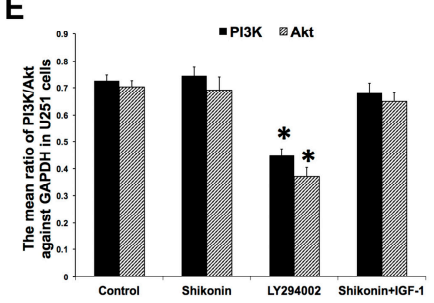

C

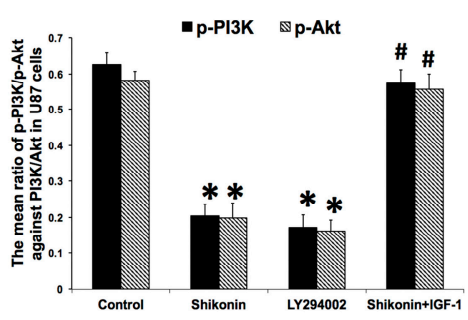

$\mathbf{F}$

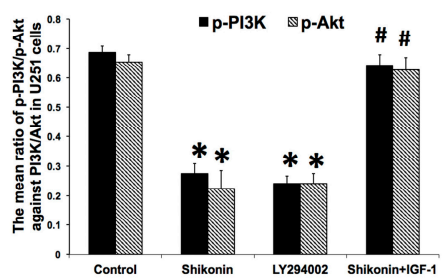

Figure 9. The effects of PI3K/Akt inhibitor or agonist on the expression of p-Akt and p-PI3K in glioma cells. U87 and U251 cell were treated with shikonin ( $5 \mu \mathrm{mol} / \mathrm{L}), \mathrm{PI} 3 \mathrm{~K} / \mathrm{Akt}$ inhibitor LY294002 $(20 \mu \mathrm{mol} / \mathrm{L})$, or shikonin combined with PI3K/Akt agonist IGF-1 $(20 \mu \mathrm{g} / \mathrm{mL})$. Only LY294002 inhibited the expression of PI3K and Akt in both cell lines compared with the control group. The expression of p-PI3K and p-Akt was inhibited by shikonin or LY294002 compared with the control group and was upregulated by the treatment of IGF-1, indicating that activation of PI3K/Akt could reverse shikonin-induced inhibition on p-PI3K and p-Akt. (A) Results of Western blot assay in U87 cells; (B) Statistical analysis of PI3K/Akt expression levels in U87 cells; (C) Statistical analysis of p-PI3K/p-Akt expression levels in U87 cells; (D) Results of Wsestern blot assay in U251 cells; (E) Statistical analysis of PI3K/Akt expression levels in U251 cells; (F) Statistical analysis of $\mathrm{p}$-PI3K/p-Akt expression levels in U251 cells. * $p<0.05$ compared with control; ${ }^{\#} p<0.05$ compared with the shikonin group $(n=3)$. 
Gliomas, highly malignant gliomas in particular, are difficult to completely eradicate by surgical resection followed by radiation therapy and chemotherapy. Recently, studies have revealed that various agents extracted from traditional Chinese medicine exhibit inhibitory effects on gliomas. For example, panaxydol, isolated from Chinese traditional herb Panax notoginseng, inhibited the proliferation and induced the differentiation of C6 glioma cells in a dose-dependent manner [13]. Curcumin, extracted from the spice turmeric, had a pro-apoptosis effect against glioma cells [14]. Our previous study revealed that artemether, the methyl ether derivative of artemisinin isolated from the plant of Artemisia annua, significantly inhibited the migration and invasiveness as well as promoting apoptosis in U87 cells [8]. With such a background, it is reasonable to believe that traditional Chinese herbs and their extracts may be potentially valuable in the treatment of glioblastoma due to their high efficiency and less systemic side effects.

Shikonin is the naphthoquinone derived from the dried roots of Lithospermum erythrorhizon, a traditional Chinese medicine plant. Studies carried out over the past 30 years have increased interest in shikonin since it has many beneficial properties such as anti-inflammatory, antithrombotic, antimicrobial, and anti-tumor effects [15]. Recently, the inhibitory effects of shikonin against various systemic malignant tumors have been well documented [16-20]. However, studies about the effect of shikonin in central nervous system (CNS) malignant tumors still remain very limited. A previous study revealed that shikonin promoted autophagy in human pancreatic cancer cells at 2.5 and $5 \mu \mathrm{mol} / \mathrm{L}$ [20]. Shikonin functioned as a proteasome inhibitor and a necroptosis inducer in multiple myeloma cells at concentrations of $2.5-5 \mu \mathrm{mol} / \mathrm{L}$ [31]. Another study reported that shikonin induced autophagy at a low dose of $2.5 \mu \mathrm{mol} / \mathrm{L}$ in human hepatocellular carcinoma cells [19]. In our previous study, we demonstrated that shikonin significantly induced cell cycle arrest in G0/G1 and S phases and promoted apoptosis by downregulating Bcl-2 expression and activating the caspase 9/3-dependent pathway at $2 \mu \mathrm{mol} / \mathrm{L}$ [21]. Therefore, in the present study, concentrations of $2.5,5$, and $7.5 \mu \mathrm{mol} / \mathrm{L}$ were selected for our experiments and the results confirmed that shikonin inhibited the proliferation of human malignant glioma U87 and U251 cell lines in a time- and dose-dependent manner, which was in accordance with our previous data and the literature [21,23]. At the concentration of $2.5 \mu \mathrm{mol} / \mathrm{L}$, shikonin did not exhibit obvious inhibition on cell viability until $48 \mathrm{~h}$, whereas the two higher concentrations displayed significant inhibitory effects starting from $12 \mathrm{~h}$. The time point at which shikonin inhibits cell proliferation is different with the former study, possibly due to the fact that there might be variance in cell sensitivities to shikonin. At $72 \mathrm{~h}$, cell viability decreased to a very low level and no significant difference could be observed between 5 and $7.5 \mu \mathrm{mol} / \mathrm{L}$. We suppose that the cell survival was heavily damaged after a long period of exposure to shikonin and the accumulation of metabolic waste and cytotoxic effects would interfere with the results. Glioblastomas are difficult to cure and often recurrent because of their aggressive invasive growth pattern, unclear boundaries between tumor and normal brain tissues, and the presence of intracranial metastatic and satellite lesions [32].

Perivascular invading growth is the major growth pattern that contributes to the development of glioblastomas and the diffusely infiltrative nature of malignant gliomas is the main obstacle to successful treatments [11,33]. Therefore, therapies and therapeutic agents that are efficient at controlling the migratory and invasive capacities of glioblastoma cells are essential. We focused on whether shikonin would influence the migratory and invasive capacities of glioblastoma cells, which are the two major biological aspects in the malignant behavior of glioblastoma. Results of in vitro Transwell and scratch 
wound healing assays confirmed that shikonin inhibited the migration and invasion of both cell lines in a dose-dependent manner.

The next question we were interested in was the related mechanism involved in this process. Matrix metalloproteinases (MMPs) are important proteolytic enzymes that degrade the extracellular matrix (ECM), which is considered to be the barrier against glioma metastasis. The activity of MMPs is essential in the metastasis and invasion of gliomas. In the family of MMPs, MMP-2 and MMP-9 are highly expressed in glioma tissues [28,34]. The two MMPs are the most important proteolytic enzymes that degrade ECM to provide efficient space for the glioma to extend [28,34,35]. Furthermore, blocking of MMP-2 and MMP-9 results in attenuated invasion of human malignant glioma cells [35]. Our previous study also revealed that artemether reduced the migration and invasion of glioma cells by inhibiting MMP-2 and MMP-9 [8]. In the present study, we investigated the expression and activity of MMP-2 and MMP-9 and found that the expression and activity were inhibited by the treatment of shikonin in a dose-dependent manner in both cell lines. As described above, shikonin inhibited the migration and invasion of U87 and U251 cells. Given these results, it is reasonable to infer that shikonin exhibited inhibitory effects on glioma cell migration and invasion by inhibiting the expression and activity of MMP-2 and MMP-9.

It has been reported that the $\mathrm{Wnt} / \beta$-catenin pathway plays an important role in the tumorigenesis and progression of gliomas [36]. $\beta$-catenin is upregulated and accumulated in the cytoplasm and nucleus of glioma cells compared to the normal brain tissue and the expression levels are positively correlated with histological malignancy [37,38]. Accumulated $\beta$-catenin also promotes the proliferation, migration, and invasion of glioma cells $[39,40]$. Furthermore, knockdown of $\beta$-catenin inhibits cell proliferation and induces apoptotic cell death in U251 cells [24]. Deregulation of $\beta$-catenin correlates to the tumorigenesis of gliomas. Since the first step in $\beta$-catenin degradation is phosphorylation by CK1 $\alpha$ on the multiprotein destruction complex [25], we investigated the expression levels of $p$ - $\beta$-catenin with the treatment of shikonin. U87 and U251 cells were treated with shikonin at the concentrations of $2.5,5$, and $7.5 \mu \mathrm{mol} / \mathrm{L}$ for $48 \mathrm{~h}$. Interestingly, the results showed contrary trends in the two cell lines. The expression of $\mathrm{p}-\beta$-catenin Y333 was significantly inhibited in U87 cells but upregulated in U251 cells. However, p- $\beta$-catenin Ser45 expression was not changed by shikonin, meaning that it was not involved in the process. The contrary trend in $\mathrm{p}$ - $\beta$-catenin Y333 expression might be due to the following reason. The two cell lines used in this study have different p53 status. U87 cells are p53 wild-type glioblastoma cells while U251 cells are p53 mutant $[41,42]$. It was previously reported that $\beta$-catenin expression was regulated by the p53 pathway: upregulated or accumulated p53 reduced $\beta$-catenin expression [43]. However, the downregulation of $\beta$-catenin could only be obtained by wild-type p53 rather than cancer-associated mutant type p53 [43]. On the other hand, p53 mutation could induce aberrant accumulation of $\beta$-catenin in various human cancers [44]. This may explain why $\beta$-catenin expression was constant in p53 mutant U251 cells. Treatment of shikonin possibly induced downregulation of $\beta$-catenin Y333 in p53 wild-type U87 cells. However in U251 cells, $\beta$-catenin could not be regulated by mutant p53 and the downstream ubiquitin-proteasome-dependent degradation of $\beta$-catenin was activated, which promoted $p$ - $\beta$-catenin Y333 expression in U251 cells. In this work, we confirmed that p- $\beta$-catenin Y333 knockdown or overexpression could attenuate or enhance the migration, invasion, MMP expression and activity in U87 cells. MMP-2 and MMP-9 are the downstream targets of $\beta$-catenin $[45,46]$. Meanwhile, it has been established that $\beta$-catenin knockdown resulted in inhibited expression of MMP-2 and MMP-9 [47]. 
Downregulated $\beta$-catenin expression leads to decreased expression of MMP-2 and MMP-9 [47,48]. Therefore, attenuated $\beta$-catenin expression as well as downstream MMP-2 and MMP-9 inhibition might be one of the potential mechanisms in the shikonin-induced inhibition of glioma cell migration and invasion.

Shikonin inhibited the proliferation, migration, and invasion in both cell lines by inhibiting MMP-2, MMP-9 and targeting p- $\beta$-catenin Y333. Shikonin possibly displayed inhibitory effects via different pathways in the two cell lines. In p53 wild-type U87 cells, shikonin possibly inhibited p- $\beta$-catenin expression via the p53 pathway. In p53 mutant U251 cells, shikonin might promote degradation of $\beta$-catenin by activating GSK3, displaying promoted expression of $p$ - $\beta$-catenin in U251 cells. Nevertheless, the precise mechanism in the shikonin-induced regulation of $p$ - $\beta$-catenin Y333 may be complicated and remains unclear. GSK3 $\beta$ function might be spared in p53 mutation-induced $\beta$-catenin accumulation [49]. Axin, another important component of the multiprotein destruction complex against $\beta$-catenin, interacts with $\mathrm{p} 53$ and regulates the activity of the p53 pathway to control cell death and growth [50]. All these factors might be involved in the shikonin-induced regulation of $p$ - $\beta$-catenin Y333, which merits further research. The $p$ - $\beta$-catenin changes are not necessary for mediating the inhibitory effects of shikonin in p53 mutant glioma cells. Taking these studies together, it is reasonable to infer that shikonin inhibited the expression and activity of MMP-2 and MMP-9 by downregulating phosphorylated $\beta$-catenin Y333 in p53 wild-type U87 cells. Therefore, $p$ - $\beta$-catenin Y333, rather than $\mathrm{p}-\beta$-catenin Ser45, might be involved in the shikonin-induced inhibition in p53 wild-type glioma cells.

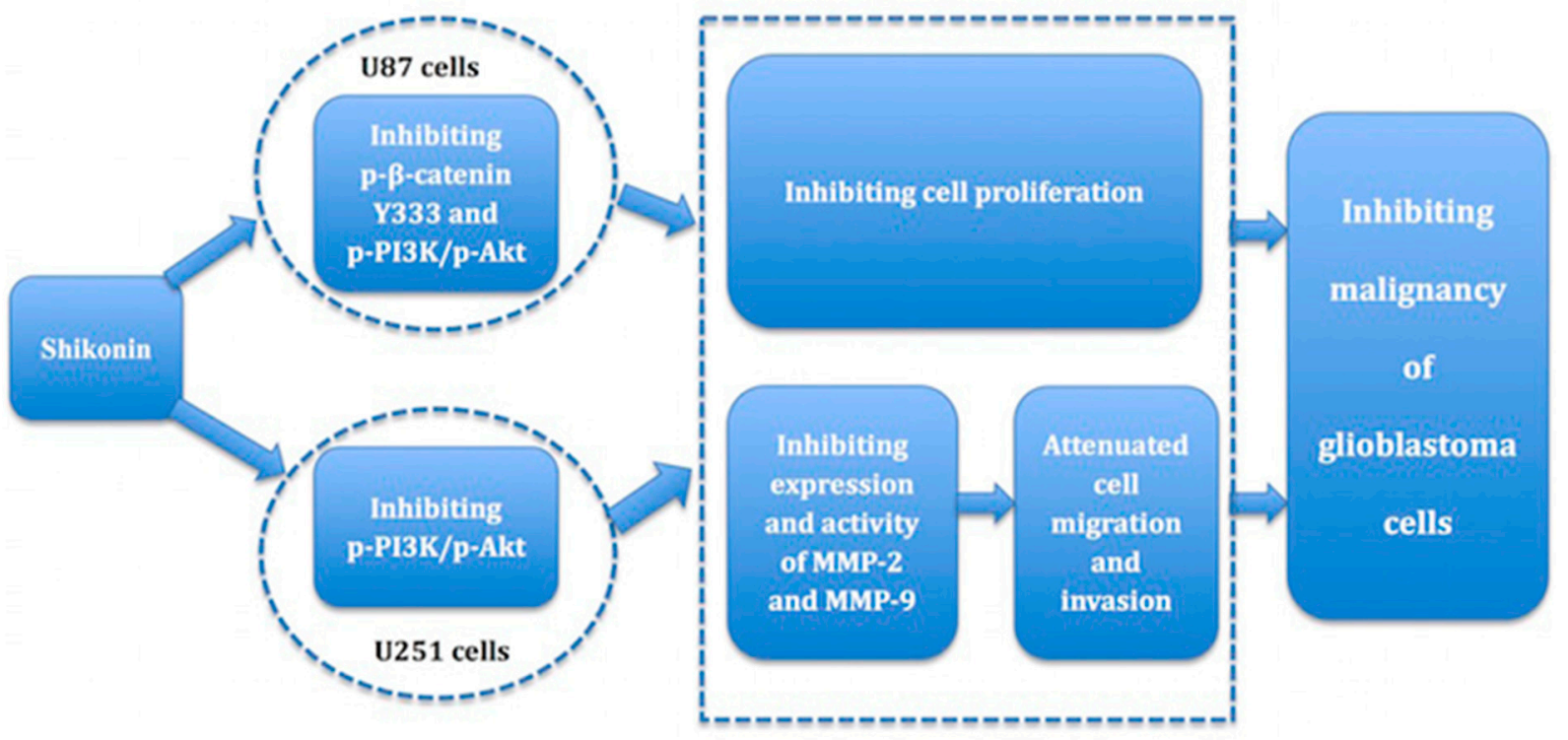

Figure 10. A scheme of the effects of shikonin on U87 and U251 human glioblastoma cells. The schematic diagram demonstrates the effects of shikonin on the malignant behavior of U87 and U251 human glioblastoma cells. The mechanisms in the two cell lines might be different. Shikonin inhibited the proliferation, migration, and invasion of glioma cells by inhibiting MMP2 and MMP9 and targeting p- $\beta$-catenin Y333 and p-PI3K/p-Akt in p53 wild-type U87 cells. Shikonin inhibited the malignant behavior of U251 cells by targeting the PI3K/Akt pathway without influencing phosphorylated $\beta$-catenin Y333. 
As described above, $\beta$-catenin might not the responsible pathway in the shikonin-induced inhibition in U251 cells. Phosphoinositide-3-kinase (PI3K) is an important signaling pathway responsible for various crucial cellular processes [51]. It has been established that the function of shikonin is also associated with the PI3K/Akt pathway [30]. Our previous work revealed that the PI3K pathway was involved in the inhibition of glioma cells induced by Chinese herbal extracts [8]. Therefore, here we also investigated the role of the PI3K/Akt pathway in the process. Inhibition of Akt and PI3K could lead to decreased expression and activity of MMP-2 and MMP-9 in cancer cells [52,53]. As shown in Figure 7, treatment with shikonin inhibited p-PI3K and p-Akt in a dose dependent manner in both cell lines, suggesting that p-Akt and p-PI3K could be involved in the shikonin-induced inhibition of glioma cells. Finally we investigated the role of PI3K/Akt pathway in the migration, invasion, and MMP expression and activity of glioma cells. As shown in Figures 8 and 9, shikonin and PI3K/Akt pathway inhibitor LY294002 attenuated the migration, invasion, and MMP expression and activity as well as the expression of p-PI3K and p-Akt in U87 and U251 cells; PI3K/Akt pathway agonist IGF-1 could reverse the inhibitory effects. The above results revealed that in p53 wild-type U87 cells, shikonin inhibited the activity of MMP-2 and MMP-9 by downregulating phosphorylated $\beta$-catenin Y333 and p-PI3K/p-Akt, leading to attenuate migration and invasion. However, in p53 mutant U251 cells, shikonin played an inhibitory role by inhibiting the PI3K/Akt pathway. The findings of this work were summarized in Figure 10. Other signaling pathways might also be involved in this process, which merits deeper research in future studies.

\section{Experimental Section}

\subsection{Cell Culture}

The human U87 MG and U251 glioblastoma cell lines were purchased from Nanjing KGI Biotechnology Co., Ltd. (Nanjing, China). U87 and U251 cells were cultured in Dulbecco's Modified Eagle Medium (DMEM) (Hyclone: Logan, UT, USA) supplemented with 10\% fetal bovine serum (FBS) (Hyclone). Both glioblastoma cell lines were cultured in an incubator at $37{ }^{\circ} \mathrm{C}$ in a humidified atmosphere of $5 \% \mathrm{CO}_{2}$.

\subsection{P- $\beta$-Catenin Knockdown and Overexpression Stable Transfection}

Cells were seeded into 24-well plates (Corning, NY, USA) until they reached $50 \%-60 \%$ confluence prior to transfection. Then the stable transfection was performed. Cells were divided into the following groups: the control, shRNA-p- $\beta$-catenin Y333, sh-negative control (sh-NC) group (transfected with empty plasmid), pIRES2-p- $\beta$-catenin Y333, and pIRES2-NC. Four short hairpin RNAs (shRNA) targeting on human p- $\beta$-catenin Y333 gene were designed and synthesized by Shanghai Jima pharmaceutical technology (Shanghai, China). The most applicable shRNA (shRNA-p- $\beta$-catenin) was identified by G418 concentration gradient screening (Sigma: St. Louis, MO, USA) and applied in the following experiments. The sequence of shRNA- $\beta$-catenin was Sense: 5 '-CACCGGATGTGGATACCT CCCAAGTTTCAAGAGAACTTGGGAGGTATCCACATCCTTTTTTG-3'; Antisense: 5'-GATCCA AAAAAGGATGTGGATACCTCCCAAGTTCTCTTGAAACTTGGGAGGTATCCACATCC-3'. The sequence of sh-negative control (sh-NC) was Sense: 5'-CACCGTTCTCCGAACGTGTCACGTTTC 
AAGAGAACGTGACACGTTCGGAATTTTTTG-3'; Antisense: 5'-GATCCAAAAAATTCTCCGAA CGTGTCACGTTCTCTTGAAACGTGACACGTTCGGAGAAC-3'. In order to enable $p$ - $\beta$-catenin to be overexpressed, gene M333 was transfected into pIRES2-EGFP expression vectors by standard procedures and confirmed by restriction digestion and DNA sequencing (pIRES2-p- $\beta$-catenin-EGFP) (GenePharma: Shanghai, China). An empty vector, pIRES2-EGFP, was used as a control. U87 cells were transfected by Lipofectamine LTX (GenePharma: Shanghai, China) and plus reagent (Invitrogen) according to the manufacturer's manual. The medium containing transfection reagents was replaced with DMEM supplemented with 10\% FBS $18 \mathrm{~h}$ after transfection. The cells were collected $48 \mathrm{~h}$ after transfection and prepared for protein extraction. The transfection efficiency of $p$ - $\beta$-catenin was tested by Western blot (described below).

\subsection{Cell Proliferation Assay}

Cell proliferation was measured with CCK8 assay kit (Sigma: St. Louis, MO, USA) according to the literature [54]. Briefly, U87 and U251 cells were seeded into 96-well plates (Corning) at a density of $1 \times 10^{4}$ cells per well in standard DMEM and incubated for $24 \mathrm{~h}$ under standard conditions $\left(37{ }^{\circ} \mathrm{C}\right.$ and $5 \% \mathrm{CO}_{2}$ ). Our previous data showed that the IC50 values of shikonin at $24 \mathrm{~h}$ were $1.84 \pm 0.34 \mu \mathrm{mol} / \mathrm{L}$ for U251 cells and $2.02 \pm 0.44 \mu \mathrm{mol} / \mathrm{L}$ for U87 cells [21]. Therefore, the concentrations used in this study were $2.5,5$, and $7.5 \mu \mathrm{mol} / \mathrm{L}$. Then the medium was replaced with either blank, serum-free DMEM or DMEM containing shikonin at concentrations of $2.5,5$, and $7.5 \mu \mathrm{mol} / \mathrm{L}$. The total volume in each well was $200 \mu \mathrm{L}$. Glioma cells were incubated in these solutions for $0,12,24,36,48$, or $72 \mathrm{~h}$ followed by treatment with $20 \mu \mathrm{L}$ of CCK8 in each well for another $1.5 \mathrm{~h}$ at $37^{\circ} \mathrm{C}$. Finally, the plates were shaken softly and the optical density was recorded at $570 \mathrm{~nm}$ (OD570) using an ELISA plate reader (SYNERGY4, Winooski, VT, USA). At least three independent experiments were performed. The inhibition rate was calculated using the following formula: (ControlOD570-Experimental group OD570)/ControlOD570 × 100\%.

\subsection{In Vitro Migration Assay}

The migratory capacity of human glioblastoma cells was evaluated in 24-well plates with Transwell inserts of $8-\mu \mathrm{m}$ pore size (Corning Costar) according to the literature [55]. Parental U87 or U251 cells were trypsinized and resuspended in serum-free DMEM at the density of $5 \times 10^{5} / \mathrm{mL}$ and $200 \mu \mathrm{L}$ of cell suspension was added into the upper chambers. Five hundred microliters of conditioned medium (DMEM medium supplemented with 10\% FBS) were placed in the lower chambers, serving as the revulsant of cell migration. Serum-free DMEM served as a negative control. Shikonin was added in the suspension of parental U87 cells or U251 cells at the concentration of $2.5,5$, or $7.5 \mu \mathrm{mol} / \mathrm{L}$. PIRES2-p- $\beta$-catenin, shRNA-p- $\beta$-catenin, LY294002 (20 $\mu \mathrm{mol} / \mathrm{L}$, Cell Signal Technology) or shikonin (5 $\mu \mathrm{mol} / \mathrm{L})$ combined with PI3K/Akt agonist insulin-like growth factors-1 (IGF-1) (20 $\mu \mathrm{g} / \mathrm{mL}$, Proteintech) were also added. After incubation for 24 or $48 \mathrm{~h}$, the inserts were taken out and cells remaining on the upper surface of the filters were carefully removed with a cotton wool swab. The cells migrating to the underside surface were gently washed once with PBS and fixed with methanol and glacial acetic acid (mixed at 3:1) for $30 \mathrm{~min}$ at room temperature and stained in Giemsa stain for $15 \mathrm{~min}$. The average number of migrating cells was counted in six random high-power fields $(\times 400)$. 


\subsection{Scratch Wound Healing Assay}

A scratch wound healing assay was performed to evaluate the migration ability of glioblastoma cells, as described previously [56,57]. Briefly, cells were seeded into six-well plates at a density of $1.0 \times 10^{5} /$ well until they reached $80 \%$ confluence. The scratching wounds were created in the monolayer of confluent U87 or U251 cells with a pipette tip. The width of the wounds was assessed to be the same at the beginning of the experiments. The wells were rinsed with PBS three times to remove floating cells and debris. To test the effects of shikonin on the migration of human glioblastoma cells, parental U87 or U251 cells were seeded in serum-free DMEM with or without shikonin $(2.5,5$, or $7.5 \mu \mathrm{mol} / \mathrm{L})$. Then these cells were incubated for $0-48 \mathrm{~h}$. The culture plates were incubated at $37{ }^{\circ} \mathrm{C}$ and in $5 \% \mathrm{CO}_{2}$. Wound healing was measured and recorded photographically over time using phase-contrast microscopy at 0,24 , and $48 \mathrm{~h}$.

\subsection{In Vitro Invasion Assay}

The effects of shikonin on the invasion of human glioblastoma cells were checked using Transwell invasion assay with inserts of $8-\mu \mathrm{m}$ pore size (Corning Costar), as described previously [58,59]. The membranes of Transwell filter inserts were coated with Matrigel (BD Biosciences: Sparks, MD, USA) diluted with medium at the ratio of 1:7. Parental U87 or U251 cells were prepared as described above. Five hundred microliters of DMEM supplemented with 10\% FBS were placed in the lower chambers. Serum-free DMEM served as a negative control. Shikonin $(2.5,5$, or $7.5 \mu \mathrm{mol} / \mathrm{L})$, pIRES2-p- $\beta$-catenin, shRNA-p- $\beta$-catenin, LY294002 (20 $\mu \mathrm{mol} / \mathrm{L}$, Cell Signal Technology: Danvers, MA, USA) or shikonin ( $5 \mu \mathrm{mol} / \mathrm{L})$ combined with IGF-1 $(20 \mu \mathrm{g} / \mathrm{mL}$, Proteintech: Chicago, IL, USA) was added in the suspension of cells in the upper chamber. After incubation for $0-48 \mathrm{~h}$, the inserts were taken out and prepared for observation under a microscope as described above. The average number of invasive cells was counted in six random high-power fields $(\times 400)$.

\subsection{Western Blot Assay}

In order to determine the expression of p- $\beta$-catenin, Western blot assay was performed. U87 or U251 cells were treated with shikonin at the concentrations of $2.5,5$, and $7.5 \mu \mathrm{mol} / \mathrm{L}$ for $48 \mathrm{~h}$. The cells were washed three times with ice-cold PBS to stop the stimulation. Then, the cells were collected and lysed in ice-cold radio immunoprecipitation assay lysis buffer containing $50 \mathrm{mmol} / \mathrm{L}$ Tris (PH 7.4), $150 \mathrm{mmol} / \mathrm{L} \mathrm{NaCl}, 1 \%$ Triton $\mathrm{X}-100,1 \%$ sodium deoxycholate, $0.1 \% \mathrm{SDS}, 1 \mathrm{mmol} / \mathrm{L}$ sodium orthovanadate, $50 \mathrm{mmol} / \mathrm{L}$ sodium fluoride, and $1 \mathrm{mmol} / \mathrm{L}$ EDTA (Beyotime Biotechnology, China) for $30 \mathrm{~min}$. Then the pellet was disrupted with an ultrasonic crusher and samples were centrifuged at $17,000 \mathrm{rpm}$ for $60 \mathrm{~min}$ at $4{ }^{\circ} \mathrm{C}$. The supernatant was collected as the soluble fraction and transferred to a new tube. The sample tubes were heated in a boiling water bath immediately for 5 min to denature the proteins. The protein concentration of the soluble material was determined with BCA protein assay kit (Beyotime Biotechnology: Shanghai, China), with bovine serum albumin used as a standard. Equal amounts of proteins $(20-25 \mu \mathrm{g})$ were separated by $10 \%$ SDS-polyacrylamide gel electrophoresis (PAGE) and processed for immunoblotting with a rabbit polyclonal antibody for catenin (diluted at 1:100; Santa Cruz Biotechnology, Dallas, TX, USA), a rabbit polyclonal antibody for $p$ - $\beta$-catenin (Y333) (diluted 
at 1:100; Santa Cruz), a rabbit multiple clonal antibodies for matrix metalloproteinase-2/9 (diluted at 1:100; Santa Cruz ), a rabbit polyclonal antibody for PI3K (diluted at 1:100; Santa Cruz), a rabbit polyclonal antibody for p-PI3K (diluted at 1:100; Santa Cruz), a rabbit polyclonal antibody for Akt (diluted at 1:100; Santa Cruz) and a rabbit polyclonal antibody for p-Akt (diluted at 1:100; Santa Cruz). A mouse polyclonal anti-GAPDH antibody (diluted at 1:2000; Santa Cruz) was used as an internal control. All the protein bands were scanned using Chemilmager 5500 V2.03 software, and the integrated density values (IDV) were calculated by computerized image analysis system (FluorChem 2.0: San Jose, CL, USA) and normalized with that of GAPDH.

\subsection{Gelatin Zymography Assay}

MMP-2 and MMP-9 activities were detected by gelatin zymography performed on $10 \%$ polyacrylamide gels containing $0.1 \%$ gelatin (Invitrogen, Carlsbad, CA, USA), as previously described [60]. The bands were visualized by staining for $30 \mathrm{~min}$ with a solution containing $0.1 \%$ Coomassie R-250 in $40 \%$ ethanol and $10 \%$ acetic acid, followed by destaining in a solution containing $10 \%$ ethanol and $7.5 \%$ acetic acid for $2 \mathrm{~h}$ at room temperature. Band densitometry was determined using Chemilmager 5500 V2.03 software (San Jose, CA, USA).

\subsection{Statistical Analysis}

All results were described as mean \pm S.D. Statistical analysis was performed with SPSS 20 software (New York, NY, USA). Differences between two groups were assessed using a Student's $t$-test and comparisons between multiple groups were performed using a one-way analysis of variance (ANOVA) test followed by Dunnett's post hoc test. A value of $p<0.05$ was considered to be statistically significant.

\section{Conclusions}

Shikonin attenuates the proliferation, migration, and invasion capability of human glioblastoma cells by inhibiting MMP-2, MMP-9. In p53 wild-type glioma cells, the mechanism is associated with downregulated phosphorylated $\beta$-catenin $\mathrm{Y} 333$ and p-PI3K/p-Akt expression. In p53 mutant glioma cells, it correlates to an inhibited PI3K/Akt pathway.

\section{Acknowledgments}

This work was supported by grants from the Natural Science Foundation of China (81172197, 81171131, 81272564, 81272795, 81372484, 81372682, and 81201800) and Shenyang Science and Technology Plan Projects (Nos. F15-199-1-30 and F15-199-1-57).

\section{Author Contributions}

Feng-Ying Zhang, Yi Hu, Ping Wang, Yun-Hui Liu, and Yi-Xue Xue conceived and designed the experiments; Feng-Ying Zhang and Zhong-You Que performed the experiments; Yi Hu and Feng-Ying Zhang analyzed the data; Zhen-Hua Wang, Yi-Xue Xue, and Yun-Hui Liu contributed reagents; Feng-Ying Zhang and Yi Hu wrote the paper; Feng-Ying Zhang, Yi Hu, Ping Wang, and Yi-Xue Xue revised the manuscript; all authors have read and approved the final version of the manuscript. 


\section{Conflicts of Interest}

The authors declare no conflict of interest.

\section{References}

1. Yin, C.L.; Lv, S.Q.; Chen, X.Y.; Guo, H. The role of glioma stem cells in glioma tumorigenesis. Front. Biosci. 2014, 19, 818-823.

2. Stupp, R.; Tonn, J.C.; Brada, M.; Pentheroudakis, G.; ESMO Guidelines Working Group. High-grade malignant glioma: ESMO Clinical Practice Guidelines for diagnosis, treatment and follow-up. Ann. Oncol. 2010, 21, v190-v193.

3. Lehrer, S.; Green, S.; Ramanathan, L.; Rosenzweig, K.; Labombardi, V. No consistent relationship of glioblastoma incidence and cytomegalovirus seropositivity in whites, blacks, and hispanics. Anticancer Res. 2012, 32, 1113-1115.

4. Crocetti, E.; Trama, A.; Stiller, C.; Caldarella, A.; Soffietti, R.; Jaal, J.; Weber, D.C.; Ricardi, U.; Slowinski, J.; Brandes, A.; et al. Epidemiology of glial and non-glial brain tumours in Europe. Eur. J. Cancer 2012, 48, 1532-1542.

5. Schwartzbaum, J.A.; Fisher, J.L.; Aldape, K.D.; Wrensch, M. Epidemiology and molecular pathology of glioma. Nat. Clin. Pract. Neurol. 2006, 2, 494-503.

6. Siebzehnrubl, F.A.; Reynolds, B.A.; Vescovi, A.; Steindler, D.A.; Deleyrolle, L.P. The origins of glioma: E Pluribus Unum? Glia 2011, 59, 1135-1147.

7. Stupp, R.; Hegi, M.E.; Mason, W.P.; van den Bent, M.J.; Taphoorn, M.J.B.; Janzer, R.C.; Ludwin, S.K.; Allgeier, A.; Fisher, B.; Belanger, K.; et al. Effects of radiotherapy with concomitant and adjuvant temozolomide versus radiotherapy alone on survival in glioblastoma in a randomised phase III study: 5-year analysis of the EORTC-NCIC trial. Lancet Oncol. 2009, 10, 459-466.

8. Wang, Y.B.; Hu, Y.; Li, Z.; Wang, P.; Xue, Y.X.; Yao, Y.L.; Yu, B.; Liu, Y.H. Artemether combined with shRNA interference of vascular cell adhesion molecule-1 significantly inhibited the malignant biological behavior of human glioma cells. PLOS ONE 2013, 8, e60834.

9. Lima, F.R.S.; Kahn, S.A.; Soletti, R.C.; Biasoli, D.; Alves, T.; da Fonseca, A.C.C.; Garcia, C.; Romão, L.; Brito, J.; Holanda-Afonso, R.; et al. Glioblastoma: Therapeutic challenges, what lies ahead. Biochim. Biophys. Acta 2012, 1826, 338-349.

10. Sanai, N.; Berger, M.S. Glioma extent of resection and its impact on patient outcome. Neurosurgery 2008, 62, 753-764.

11. Motsch, S.; Koschmann, C.; Calinescu, A.A.; Mineharu, Y.; Camelo-Piragua, S.I.; Orringer, D.; Bannykh, S.; Nichols, W.S.; deCarvalho, A.C.; Mikkelsen, T. Mechanisms of glioma formation: Iterative perivascular glioma growth and invasion leads to tumor progression, VEGF-independent vascularization, and resistance to antiangiogenic therapy. Neoplasia 2014, 16, 543-561.

12. Skalli, O.; Wilhelmsson, U.; Orndahl, C.; Fekete, B.; Malmgren, K.; Rydenhag, B.; Pekny, M. Astrocytoma grade IV (glioblastoma multiforme) displays 3 subtypes with unique expression profiles of intermediate filament proteins. Hum. Pathol. 2013, 44, 2081-2088. 
13. Hai, J.; Lin, Q.; Lu, Y.; Yi, J.; Zhang, H. Growth inhibition and induction of differentiation by panaxydol in rat C6 glioma cells. Neurol. Res. 2008, 30, 99-105.

14. Shao, J.; Zheng, D.; Jiang, Z.; Xu, H.; Hu, Y.; Li, X.; Lu, X. Curcumin delivery by methoxy polyethylene glycol-poly(caprolactone) nanoparticles inhibits the growth of C6 glioma cells. Acta Biochim. Biophys. Sin. 2011, 43, 267-274.

15. Andújar, I.; Ríos, J.L.; Giner, R.M.; Recio, M.C. Pharmacological properties of shikonin-A review of literature since 2002. Planta Med. 2013, 79, 1685-1697.

16. Lan, W.; Wan, S.; Gu, W.; Wang, H.; Zhou, S. Mechanisms behind the inhibition of lung adenocarcinoma cell by shikonin. Cell Biochem. Biophys. 2014, 70, 1459-1467.

17. Jang, S.Y.; Lee, J.K.; Jang, E.H.; Jeong, S.Y.; Kim, J.H. Shikonin blocks migration and invasion of human breast cancer cells through inhibition of matrix metalloproteinase-9 activation. Oncol. Rep. 2014, 31, 2827-2833.

18. Chen, Y.; Zheng, L.; Liu, J.; Zhou, Z.; Cao, X.; Lv, X.; Chen, F. Shikonin inhibits prostate cancer cells metastasis by reducing matrix metalloproteinase-2/-9 expression via AKT/mTOR and ROS/ERK1/2 pathways. Int. Immunopharmacol. 2014, 21, 447-455.

19. Gong, K.; Zhang, Z.; Chen, Y.; Shu, H.B.; Li, W. Extracellular signal-regulated kinase, receptor interacting protein, and reactive oxygen species regulate shikonin-induced autophagy in human hepatocellular carcinoma. Eur. J. Pharmacol. 2014, 738, 142-152.

20. Shi, S.; Cao, H. Shikonin promotes autophagy in BXPC-3 human pancreatic cancer cells through the PI3K/Akt signaling pathway. Oncol. Lett. 2014, 8, 1087-1089.

21. Zhang, F.L.; Liu, Y.H.; Liu, L.B.; Liu, X.B.; Xue, Y.X. Topoisomerase I inhibitors, shikonin and topotecan, inhibit growth and induce apoptosis of glioma cells and glioma stem cells. PLoS ONE 2013, 8, e81815.

22. Yang, J.T.; Li, Z.L.; Wu, J.Y.; Lu, F.J.; Chen, C.H. An oxidative stress mechanism of shikonin in human glioma cells. PLoS ONE 2014, 9, e94180.

23. Huang, C.; Luo, Y.; Zhao, J.; Yang, F.; Zhao, H.; Ge, P. Shikonin kills glioma cells through necroptosis mediated by RIP-1. PLoS ONE 2013, 8, e66326.

24. Pu, P.; Zhang, Z.; Kang, C.; Jiang, R.; Jia, Z.; Wang, G.; Jiang, H. Downregulation of Wnt2 and $\beta$-catenin by siRNA suppresses malignant glioma cell growth. Cancer Gene Ther. 2009, 16, 351-361.

25. Paul, I.; Bhattacharya, S.; Chatterjee, A.; Ghosh, M.K. Current understanding on EGFR and Wnt/ $\beta$-catenin signaling in glioma and their possible crosstalk. Genes Cancer 2013, 4, 427-446.

26. Giles, R.H.; van Es, J.H.; Clevers, H. Caught up in a Wnt storm: Wnt signaling in cancer. Biochim. Biophys. Acta 2003, 1653, 1-24.

27. Yano, H.; Hara, A.; Shinoda, J.; Takenaka, K.; Yoshimi, N.; Mori, H.; Sakai, N. Immunohistochemical analysis of $\beta$-catenin in $N$-ethyl- $N$-nitrosourea-induced rat gliomas: Implications in regulation of angiogenesis. Neurol. Res. 2000, 22, 527-532.

28. Forsyth, P.A.; Wong, H.; Laing, T.D.; Rewcastle, N.B.; Morris, D.G.; Muzik, H.; Leco, K.J.; Johnston, R.N.; Brasher, P.M.A.; Sutherland, G.; et al. Gelatinase-A (MMP-2), gelatinase-B (MMP-9) and membrane type matrix metalloproteinase-1 (MT1-MMP) are involved in different aspects of the pathophysiology of malignant gliomas. Br. J. Cancer 1999, 79, 1828-1835. 
29. Hu, Y.; Lin, X.; Wang, P.; Xue, Y.X.; Li, Z.; Liu, L.B.; Yu, B.; Feng, T.D.; Liu, Y.H. CRM197 in combination with shRNA interference of VCAM-1 displays enhanced inhibitory effects on human glioblastoma cells. J. Cell. Physiol. 2015, 230, 1713-1728.

30. Wang, L.; Gai, P.; Xu, R.; Zheng, Y.; Lv, S.; Li, Y.; Liu, S. Shikonin protects chondrocytes from interleukin-1 $\beta$-induced apoptosis by regulating PI3K/Akt signaling pathway. Int. J. Clin. Exp. Pathol. 2015, 8, 298-308.

31. Wada, N.; Kawano, Y.; Fujiwara, S.; Kikukawa, Y.; Okuno, Y.; Tasaki, M.; Ueda, M.; Ando, Y.; Yoshinaga, K.; Ri, M.; et al. Shikonin, dually functions as a proteasome inhibitor and a necroptosis inducer in multiple myeloma cells. Int. J. Oncol. 2015, 46, 963-972.

32. Hu, Y.; Cheng, P.; Ma, J.C.; Xue, Y.X.; Liu, Y.H. Platelet-derived growth factor BB mediates the glioma-induced migration of bone marrow-derived mesenchymal stem cells by promoting the expression of vascular cell adhesion molecule-1 through the PI3K, P38 MAPK and NF- $\kappa$ B pathways. Oncol. Rep. 2013, 30, 2755-2764.

33. Trog, D.; Yeghiazaryan, K.; Schild, H.H.; Golubnitschaja, O. Engineering of clinical glioma treatment: Prediction of pro-invasive molecular events in treated gliomas. Proc. Inst. Mech. Eng. H 2008, 222, 1149-1160.

34. Zhao, J.X.; Yang, L.P.; Wang, Y.F.; Qin, L.P.; Liu, D.Q.; Bai, C.X.; Nan, X.; Shi, S.S.; Pei, X.J. Gelatinolytic activity of matrix metalloproteinase- 2 and matrix metalloproteinase- 9 in rat brain after implantation of 9L rat glioma cells. Eur. J. Neurol. 2007, 14, 510-516.

35. Wang, M.; Yoshida, D.; Liu, S.; Teramoto, A. Inhibition of cell invasion by indomethacin on glioma cell lines: In vitro study. J. Neurooncol. 2005, 72, 1-9.

36. Liu, X.; Wang, L.; Zhao, S.; Ji, X.; Luo, Y.; Ling, F. $\beta$-Catenin overexpression in malignant glioma and its role in proliferation and apoptosis in glioblastma cells. Med. Oncol. 2011, 28, 608-614.

37. Sareddy, G.R.; Panigrahi, M.; Challa, S.; Mahadevan, A.; Babu, P.P. Activation of Wnt/ $\beta$-catenin/ Tcf signaling pathway in human astrocytomas. Neurochem. Int. 2009, 55, 307-317.

38. Rossi, M.; Magnoni, L.; Miracco, C.; Mori, E.; Tosi, P.; Pirtoli, L.; Tini, P.; Oliveri, G.; Cosci, E.; Bakker, A. $\beta$-catenin and Gli1 are prognostic markers in glioblastoma. Cancer Biol. Ther. 2011, 11, 753-761.

39. Yan, Z.; Wang, J.; Wang, C.; Jiao, Y.; Qi, W.; Che, S. miR-96/HBP1/Wnt/ß-catenin regulatory circuitry promotes glioma growth. FEBS Lett. 2014, 588, 3038-3046.

40. Chen, X.; Hu, W.; Xie, B.; Gao, H.; Xu, C.; Chen, J. Downregulation of SCAI enhances glioma cell invasion and stem cell like phenotype by activating Wnt/ $\beta$-catenin signaling. Biochem. Biophys. Res. Commun. 2014, 448, 206-211.

41. Chen, L.; Zhang, J.; Han, L.; Zhang, A.; Zhang, C.; Zheng, Y.; Jiang, T.; Pu, P.; Jiang, C.; Kang, C. Downregulation of miR-221/222 sensitizes glioma cells to temozolomide by regulating apoptosis independently of p53 status. Oncol. Rep. 2012, 27, 854-860.

42. Kataoka, Y.; Murley, J.S.; Patel, R.; Grdina, D.J. Cytoprotection by WR-1065, the active form of amifostine, is independent of p53 status in human malignant glioma cell lines. Int. J. Radiat. Biol. 2000, 76, 633-639. 
43. Sadot, E.; Geiger, B.; Oren, M.; Ben-Ze'ev, A. Down-regulation of $\beta$-catenin by activated p53. Mol. Cell. Biol. 2001, 21, 6768-6781.

44. Cagatay, T.; Ozturk, M. P53 mutation as a source of aberrant $\beta$-catenin accumulation in cancer cells. Oncogene 2002, 21, 7971-7980.

45. Luo, Y.; Sun, Z.; Li, Y.; Liu, L.; Cai, X.; Li, Z. Caudatin inhibits human hepatoma cell growth and metastasis through modulation of the Wnt/ $\beta$-catenin pathway. Oncol. Rep. 2013, 30, 2923-2928.

46. Pooja, T.; Karunagaran, D. Emodin suppresses Wnt signaling in human colorectal cancer cells SW480 and SW620. Eur. J. Pharmacol. 2014, 742, 55-64.

47. Zhao, C.; Zhang, M.; Liu, W.; Wang, C.; Zhang, Q.; Li, W. $\beta$-catenin knockdown inhibits pituitary adenoma cell proliferation and invasion via interfering with AKT and gelatinases expression. Int. J. Oncol. 2015, 46, 1643-1650.

48. Zhang, X.L.; Chen, M.L.; Zhou, S.L. Fentanyl inhibits proliferation and invasion of colorectal cancer via $\beta$-catenin. Int. J. Clin. Exp. Pathol. 2015, 8, 227-235.

49. Iwai, A.; Hijikata, M.; Hishiki, T.; Isono, O.; Chiba, T.; Shimotohno, K. Coiled-coil domain containing $85 \mathrm{~B}$ suppresses the $\beta$-catenin activity in a p53-dependent manner. Oncogene 2008, 27 , 1520-1526.

50. Zhang, L.Y.; Ye, J.; Zhang, F.; Li, F.-F.; Li, H.; Gu, Y.; Liu, F.; Chen, G.-S.; Li, Q. Axin induces cell death and reduces cell proliferation in astrocytoma by activating the p53 pathway. Int. J. Oncol. 2009, 35, 25-32.

51. Okkenhaug, K.; Vanhaesebroeck, B. PI3K in lymphocyte development, differentiation and activation. Nat. Rev. Immunol. 2003, 3, 317-330.

52. Ku, M.J.; Kim, J.H.; Lee, J.; Cho, J.Y.; Chun, T.; Lee, S.Y. Maclurin suppresses migration and invasion of human non-small-cell lung cancer cells via anti-oxidative activity and inhibition of the Src/FAK-ERK- $\beta$-catenin pathway. Mol. Cell. Biochem. 2015, 402, 243-252.

53. Tseng, C.H.; Tzeng, C.C.; Chiu, C.C.; Hsu, C.Y.; Chou, C.K.; Chen, Y.L. Discovery of 2-[2-(5-nitrofuran-2-yl)vinyl]quinoline derivatives as a novel type of antimetastatic agents. Bioorg. Med. Chem. 2015, 23, 141-148.

54. Ding, D.; Wei, S.; Song, Y.; Li, L.; Du, G.; Zhan, H.; Cao, Y. Osthole exhibits anti-cancer property in rat glioma cells through inhibiting PI3K/Akt and MAPK signaling pathways. Cell. Physiol. Biochem. 2013, 32, 1751-1760.

55. Li, P.; Zhou, C.; Xu, L.; Xiao, H. Hypoxia enhances stemness of cancer stem cells in glioblastoma: An in vitro study. Int. J. Med. Sci. 2013, 10, 399-407.

56. Shiozaki, A.; Bai, X.H.; Shen-Tu, G.; Moodley, S.; Takeshita, H.; Fung, S.Y.; Wang, Y.; Keshavjee, S.; Liu, M. Claudin 1 mediates TNF $\alpha$-induced gene expression and cell migration in human lung carcinoma cells. PLoS ONE 2012, 7, e38049.

57. Roos, N.; Poulalhon, N.; Farge, D.; Madelaine, I.; Mauviel, A.; Verrecchia, F. In vitro evidence for a direct antifibrotic role of the immunosuppressive drug mycophenolate mofetil. J. Pharmacol. Exp. Ther. 2007, 321, 583-589.

58. Qi, S.; Song, Y.; Peng, Y.; Wang, H.; Long, H.; Yu, X.; Li, Z.; Fang, L.; Wu, A.; Luo, W.; et al. ZEB2 mediates multiple pathways regulating cell proliferation, migration, invasion, and apoptosis in glioma. PLoS ONE 2012, 7, e38842. 
59. Bai, J.; Mei, P.J.; Liu, H.; Li, C.; Li, W.; Wu, Y.P.; Yu, Z.Q.; Zheng, J.N. BRG1 expression is increased in human glioma and controls glioma cell proliferation, migration and invasion in vitro. J. Cancer Res. Clin. Oncol. 2012, 138, 991-998.

60. Cai, H.; Xue, Y.; Liu, W.; Li, Z.; Hu, Y.; Li, Z.; Shang, X.; Liu, Y. Overexpression of Roundabout4 predicts poor prognosis of primary glioma patients via correlating with microvessel density. J. Neurooncol. 2015, 123, 161-169.

(C) 2015 by the authors; licensee MDPI, Basel, Switzerland. This article is an open access article distributed under the terms and conditions of the Creative Commons Attribution license (http://creativecommons.org/licenses/by/4.0/). 